\title{
Changes in Different Classes of Precipitation and the Impacts on Sediment Yield in the Hekouzhen-Longmen Region of the Yellow River Basin, China
}

\author{
Suzhen Dang $\mathbb{D}^{1,2}$ Xiaoyan Liu, ${ }^{3}$ Xiaoyu Li, ${ }^{4}$ Manfei Yao, ${ }^{5}$ and Dan Zhang ${ }^{6}$ \\ ${ }^{1}$ Yellow River Institute of Hydraulic Research, Yellow River Conservancy Commission, Zhengzhou 450003, China \\ ${ }^{2}$ Key Laboratory of Soil and Water Loss Process and Control on the Loess Plateau, MWR, \\ Yellow River Institute of Hydraulic Research, Zhengzhou 450003, China \\ ${ }^{3}$ Yellow River Conservancy Commission, Zhengzhou 450003, China \\ ${ }^{4}$ Hydrology Bureau of Yellow River Conservancy Commission, Zhengzhou 450004, China \\ ${ }^{5}$ School of Water Conservancy, North China University of Water Resources and Electric Power, Zhengzhou 450045, China \\ ${ }^{6}$ Key Laboratory of Watershed Geographic Sciences, Nanjing Institute of Geography and Limnology, Chinese Academy of Sciences, \\ Nanjing 210008, China
}

Correspondence should be addressed to Suzhen Dang; dangsz_hky@163.com

Received 29 May 2018; Revised 24 October 2018; Accepted 30 October 2018; Published 29 November 2018

Academic Editor: James Cleverly

Copyright (C) 2018 Suzhen Dang et al. This is an open access article distributed under the Creative Commons Attribution License, which permits unrestricted use, distribution, and reproduction in any medium, provided the original work is properly cited.

\begin{abstract}
The sediment yield of the Yellow River Basin has obviously decreased since the 1980s, and the impacts of precipitation on sediment yield changes have become increasingly important with the global climate change. The spatial and temporal variations in annual precipitation and different classes of precipitation in the Hekouzhen-Longmen region (HLR) in the middle reaches of the Yellow River Basin were investigated using data collected from 301 rainfall stations from 1966 to 2016. The impacts of precipitation variation on sediment yield were evaluated, and the hydrological modeling method was used to quantitatively assess the attribution of precipitation and other factors to sediment yield changes in the HLR. The results show that the annual precipitation and $P_{10}$ increased from the northwest to the southeast of the HLR, suggesting it was drier in the northwest region of the HLR. $P_{25}$ and $P_{50}$ were mainly concentrated in the northwestern and southwestern parts of the HLR, reflecting that heavy rain was more likely to occur in these regions of the HLR. All of the annual precipitation and different classes of precipitation had no significant changing trends from 1966 to 2016, and the relationship between rainfall and sediment yield obviously changed in 2006 . Compared with the average annual mean values from 1966 to 2016, both the annual precipitation and the different classes of precipitation were higher in the HLR during 2007-2016. The sediment yield decrease during 1990-1999 was mainly influenced by precipitation, while other factors were the main driving factor for the sediment yield decrease in the periods of 1980-1989, 2000-2009, and 2010-2016, and other factors have become the dominant driving factors of the sediment yield change in the HLR since 2000 .
\end{abstract}

\section{Introduction}

The Yellow River is known for its large sediment discharge and high sediment concentration, and $98 \%$ of its sediment originates from the area above the Shaanxian (Tongguan) station on the main channel of the Yellow River. During the natural period (i.e., 1919-1960), the average annual sediment discharge of the Shaanxian was 1.6 billion tons. However, the sediment discharge of the Yellow River has obviously decreased since the 1980s [1]. The average annual sediment discharge of the Tongguan station was only 539 million and 248 million tons for the periods of 1980-2016 and 20002016, representing decreases of $66.3 \%$ and $84.5 \%$, respectively. Since precipitation is a direct influencing factor 
on sediment yield, determining changes in precipitation and identifying their impact on sediment discharge have become a topic of great concern in recent years.

In this paper, we selected the region from Hekouzhen to Longmen in the middle reaches of the Yellow River Basin (hereinafter referred to as the HLR) as the study area, which is located in the Loess Plateau and represents the most seriously affected area of water and soil loss and is the concentrated source area of sediment and coarse sediment [2]; additionally, this region is one of the three storm flood source areas in the middle reaches of the Yellow River [3]. The soil erosion area occupies $83.45 \%$ of the total area in the HLR, and the average annual sediment discharge is 908 million tons, accounting for $57 \%$ of the sediment discharge from the Tongguan station; furthermore, the average annual coarse sediment discharge is 223.6 million tons, accounting for $72 \%$ of the annual coarse sediment discharge of the Yellow River [2].

To date, many scholars have conducted relevant studies on the changes in precipitation in this region. Kang et al. analyzed the spatial distribution and temporal variation of precipitation in the HLR from 1955 to 1995 [4]. Hu et al. found out that compared with the baseline period before 1969 , the precipitation in the HLR decreased by $7 \%, 11 \%$, and $13 \%$ in the 1970s, 1980s, and 1990s, respectively [5]. Compared with 1956-1996, the precipitation in the upper and middle reaches of the Yellow River decreased from 1997 to 2006; additionally, the rainfall in July and August in the HLR decreased by $17 \%$ [6]. Based on the precipitation data collected from 74 rainfall stations located in the five tributaries of the HLR between 1980 and 2009, the precipitation increased slightly during the flood season, but the rainfall intensity was significantly smaller [7]. Sun et al. [8] analyzed changes in the mean and extreme temperature and precipitation values in the Loess Plateau between 1961 and 2011 using a gridded dataset and found out that the total amount of precipitation on wet days decreased over a large area of the Loess Plateau, and there were only minor changes in extreme precipitation over the Loess Plateau. Other studies have analyzed the changes in precipitation in the Yellow River Basin by using the observed precipitation data collected at dozens of weather stations by the National Meteorological Bureau [9-12], and most of the studies focused on the changes in annual precipitation and precipitation during the flood season [13-15]. In contrast, little research has been focused on the different classes of precipitation that have significant impacts on sediment yield. In view of the uneven spatial distribution of precipitation, we collected data from more additional rainfall stations, which provided more information than the previous studies.

Using the observed precipitation data collected at 301 rainfall stations in the HLR from 1966 to 2016, the objectives of this study were (i) to analyze the spatial distribution and temporal variation in the annual precipitation, different precipitation classes, and rainstorm frequency and (ii) to explore the impacts of precipitation on sediment yield and quantitatively analyze the contribution of precipitation and other factors to sediment yield change.

\section{Study Area and Data}

2.1. Study Region. The study area is the Hekouzhen-Longmen region, which is situated in the middle reaches of the Yellow River (Figure 1), with an area of $111,586 \mathrm{~km}^{2}$ between $108^{\circ} 02^{\prime} \sim 112^{\circ} 44^{\prime} \mathrm{E}$ and $35^{\circ} 40^{\prime} \mathrm{N} \sim 40^{\circ} 34^{\prime} \mathrm{N}$, accounting for $14.8 \%$ of the total area of the Yellow River Basin [14]. The length of the main stream of the Yellow River in the study area is $723 \mathrm{~km}$. There are 21 large tributaries with a catchment area larger than $1000 \mathrm{~km}^{2}$. The high sediment yield area in the HLR is $71,600 \mathrm{~km}^{2}$ and accounts for $60.1 \%$ of the total high sediment yield area in the entire Yellow River Basin; additionally, the high sediment yield area in the HLR accounts for $64.2 \%$ of the study area. The terrain is dominated by the gully region of the Loess Plateau and belongs to the temperate continental monsoon climate. The annual average temperature is $6-14^{\circ} \mathrm{C}$, and the average annual precipitation is $290-620 \mathrm{~mm}$ and is mainly concentrated in July-September.

\subsection{Data}

2.2.1. Rainfall Stations. Considering the equal distribution of rainfall stations and the integrity of data, this study used daily precipitation data collected from 301 selected rain gauge stations during the period from 1966 to 2016. The rainfall station locations are shown in Figure 1. The precipitation data of 292 rainfall stations and the sediment discharge data are from the hydrological yearbook and the Hydrological Bureau of Yellow River Conservancy Commission; additionally, data from 9 meteorological stations were provided by China Meteorological Administration (CMA). Among the 301 rainfall stations, a total of 150 rainfall stations were established before 1966; the remaining rainfall stations were established between 1967 and 1976.

2.2.2. Rainfall Factor. In consideration of the impact of precipitation on sediment yield in the study area, the rainfall factors selected in this paper included annual precipitation $(P)$ and different classes of precipitation. The different precipitation classes refer to the total annual rainfall values, and categories were divided based on daily precipitation amounts that were greater than $10 \mathrm{~mm}, 25 \mathrm{~mm}, 50 \mathrm{~mm}$, and $100 \mathrm{~mm}$, which were expressed as $P_{10}, P_{25}, P_{50}$, and $P_{100}$, respectively, and were measured in $\mathrm{mm}$. The different classes of precipitation not only reflect the impact of total precipitation on sediment yield but also reflect the impact of precipitation intensity on sediment yield [16].

2.2.3. Regional Average Precipitation. First, the annual precipitation, $P_{10}, P_{25}, P_{50}$, and $P_{100}$ of each rainfall station were calculated, and then the average precipitation in the entire study area was interpolated by the Thiessen polygon method.

2.2.4. Rainstorm Frequency. To objectively reflect the change in the frequency of heavy rain events with daily precipitation higher than $50 \mathrm{~mm}$, the ratio of the number of rainfall stations 


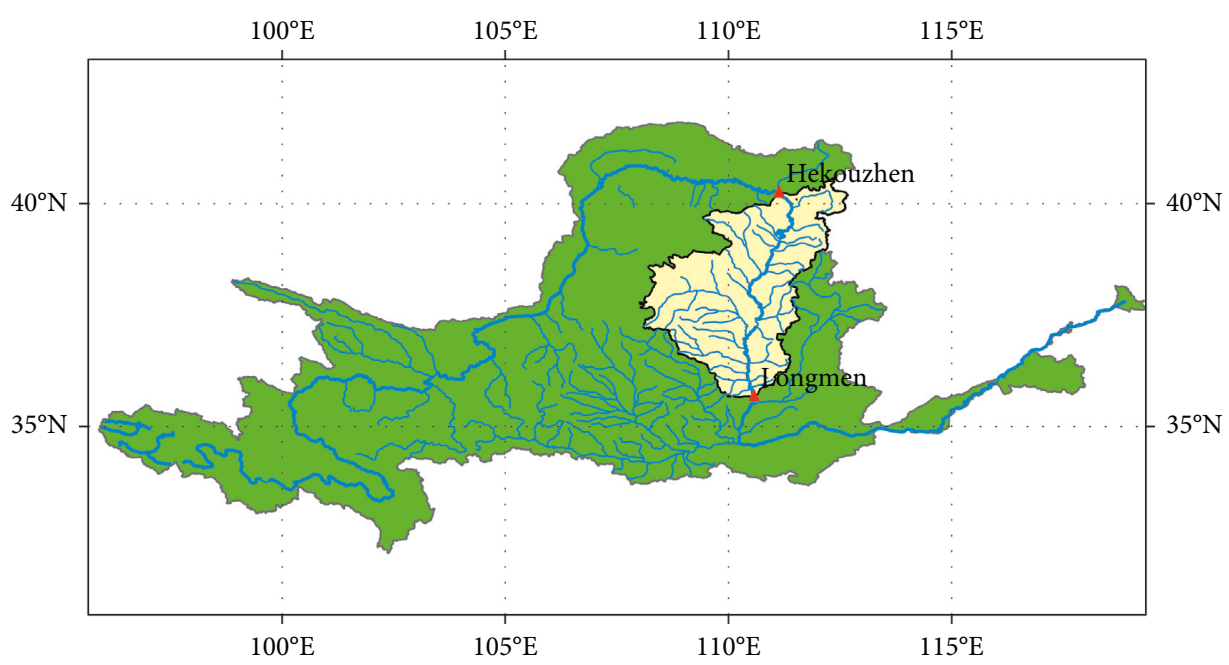

(a)

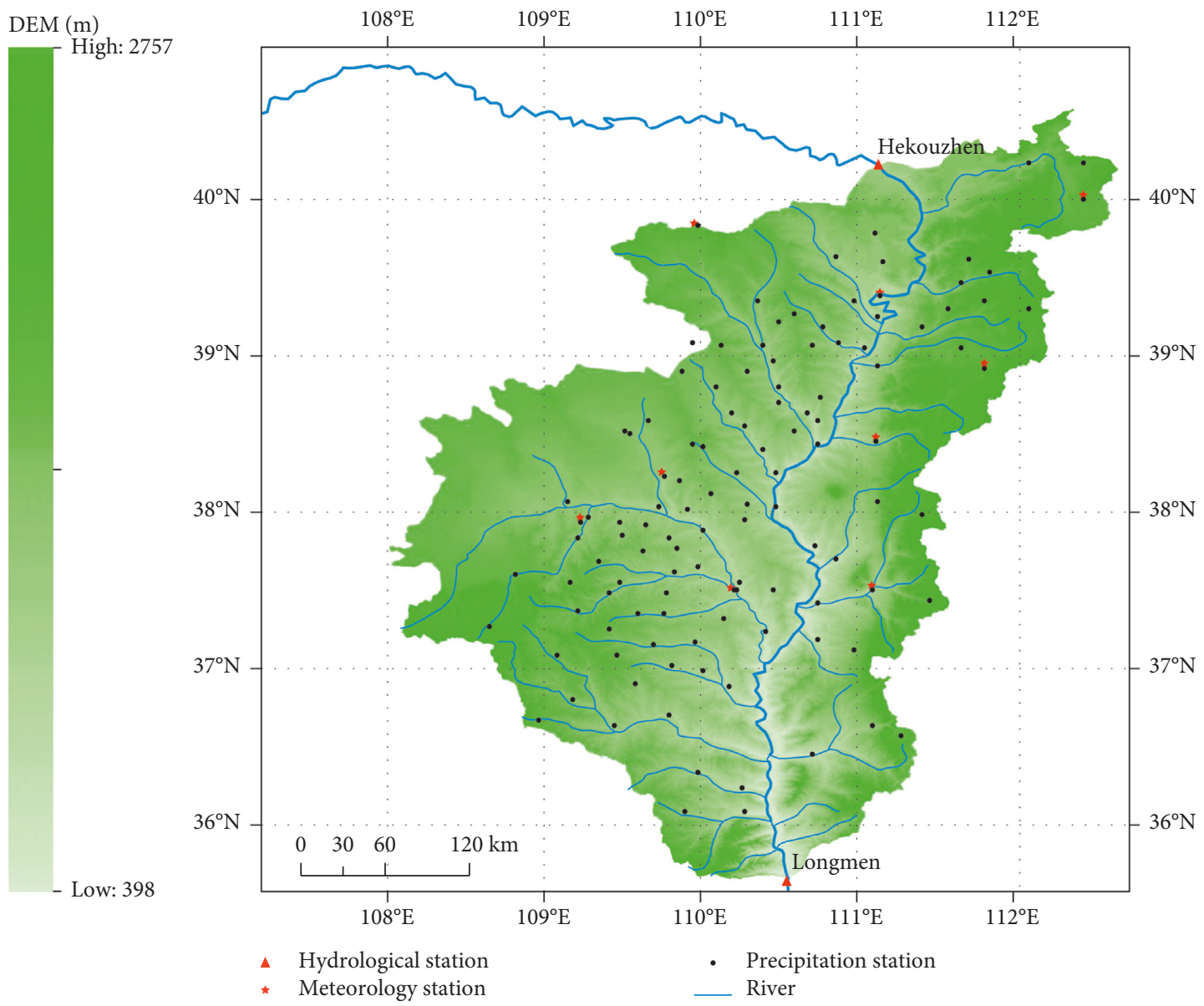

(b)

Figure 1: Sketch map of the study area.

with daily precipitation greater than $50 \mathrm{~mm}$ in a given year to the total number of rainfall stations participating in rainfall measurements in the same year was referred to as the rainstorm frequency. Similarly, the frequency of heavy rainstorms can be calculated by the number of rainfall stations with daily precipitation greater than $100 \mathrm{~mm}$.

\section{Methodology}

3.1. Double Mass Curve. The double mass curve (DMC) method is the simplest, most intuitive, and most widely used method for consistency analysis of long-term evolutionary trends of hydrological and meteorological elements [17, 18]. 
By establishing a double cumulative curve that excludes the influence of the reference variable, whether another factor leads to significant trend changes in the tested variable is revealed [19]. The DMC can analyze changing trends in runoff and sediment discharge, and this method has been widely used in the study on water and sediment effects of water and soil conservation measures [20-22]. Changes in the slope of the double mass curve between precipitation and sediment discharge reflect changes in sediment discharge that are produced by unit of rainfall.

3.2. Mann-Kendall Test. The Mann-Kendall (MK) test is a nonparametric method and is recommended by the World Meteorological Organization [23-25]. The MK test does not require samples to follow a specific distribution, and the results are not affected by a few abnormal values. The MK test is suitable for nonnormally distributed data and has been widely used in assessing the changing trends of hydrological and meteorological time series data [26-28]. The MK test was applied to analyze the changes in precipitation in the study area. The MK test will not be discussed here, as its detailed description can be found in many studies [29, 30]. Mann-Kendall $Z$ statistics greater than 1.96 indicated a significant increasing trend at the significance level of $P=0.05$, while a $Z$ statistic less than -1.96 indicated a significant decreasing trend.

3.3. Calculation Method of Precipitation Change. To eliminate the influence of changes affiliated with the rainfall stations on the calculated average watershed precipitation as much as possible, the establishment time and spatial distribution of the rainfall stations were considered, and the multiyear average annual precipitation from 1966 to 2016 was identified as the reference precipitation. Daily precipitation was collected from 150 rainfall stations established before 1966 for the period from 1966 to 2016, and the spatial distribution of the annual precipitation, $P_{10}, P_{25}, P_{50}$, and $P_{100}$ was spatially interpolated by the Thiessen polygon method. The average annual precipitation for the period from 2007 to 2016 was calculated by using the precipitation data collected from all rainfall stations.

The measured data from 1966 to 2016 were used to calculate the average precipitation for all the rainfall stations established before 1966. For the rainfall stations without measured data from 1966 to 1976, the average precipitation from 1966 to 2016 was extracted from the precipitation spatial distribution maps. By comparing the current annual precipitation with the multiyear average precipitation at each station, the annual abundance and spatial distribution of precipitation could be determined for each station.

3.4. Quantitative Assessment of the Changes in Sediment Yield. For a given basin, the changes in observed sediment yield under the impacts of precipitation and other factors can be expressed as follows:

$$
\Delta W_{\mathrm{S}}=\Delta W_{\mathrm{SP}}+\Delta W_{\mathrm{SH}},
$$

where $\Delta W_{\mathrm{S}}$ is the observed sediment yield difference between the impacted period and the baseline period and $\Delta W_{\mathrm{SP}}$ and $\Delta W_{\mathrm{SH}}$ represent the changes in sediment yield due to precipitation and other factors, respectively. To quantitatively identify the impact of precipitation and other factors on the sediment yield changes, the hydrological modeling method can be used. Here, the empirical model was considered due to its good performance in modeling the sediment yield in the middle reaches of the Yellow River Basin [1, 31]. The relationship between precipitation and sediment yield of the HLR in the baseline period is given as follows [1]:

$$
W_{\mathrm{S}}=481.1 \times P_{2.5}^{1.059} \text {, }
$$

where $W_{\mathrm{S}}$ is the sediment yield and $P_{2.5}$ is the rainfall factor.

The effects of precipitation change and other factors on sediment yield can be calculated as follows:

$$
\begin{aligned}
& \Delta W_{\mathrm{SP}}=W_{\mathrm{S} 0}-W_{\mathrm{S} 2}, \\
& \Delta W_{\mathrm{SH}}=W_{\mathrm{S} 2}-W_{\mathrm{S} 1},
\end{aligned}
$$

where $W_{\mathrm{S} 0}$ is the sediment yield in the baseline period and $W_{\mathrm{S} 1}$ and $W_{\mathrm{S} 2}$ are the observed and calculated sediment yields in impacted periods, respectively. Taking into account the change in the underlying surface and other factors such as the change in the relationship between precipitation and sediment yield, the baseline period of the HLR is from 1956 to 1977; for more details, the readers can refer to Liu [1].

\section{Results and Discussion}

\subsection{Spatial-Temporal Variations in Precipitation from 1966 to 2016}

4.1.1. Spatial Distribution of Precipitation. Figure 2 shows the spatial distribution of the average annual precipitation and the different classes of precipitation in the study area based on the measured precipitation data from 1966 to 2016. The annual precipitation tended to increase gradually from the northwest to the southeast. $P_{10}$ and the annual precipitation had basically the same spatial distribution. However, $P_{25}$ and $P_{50}$ were mainly concentrated in the northwestern and southwestern parts of the HLR, with annual precipitation amounts of 450-600 $\mathrm{mm}$.

4.1.2. Change in Annual Precipitation. Figure 3 shows the change in annual precipitation in the HLR from 1966 to 2016. The average annual precipitation during the 51-year period was $443.6 \mathrm{~mm}$, the maximum annual precipitation was $617.2 \mathrm{~mm}$ (in 2016), and the minimum annual precipitation was $291.2 \mathrm{~mm}$ (in 1999).

Since the beginning of the twenty-first century, precipitation in the HLR has been more abundant than the overall multiyear average annual precipitation. The average annual precipitation during 2000-2016 was $483.5 \mathrm{~mm}$; however, the precipitation was higher in the years 2003, 2007, 2012, 2013, and 2016. In terms of the precipitation 


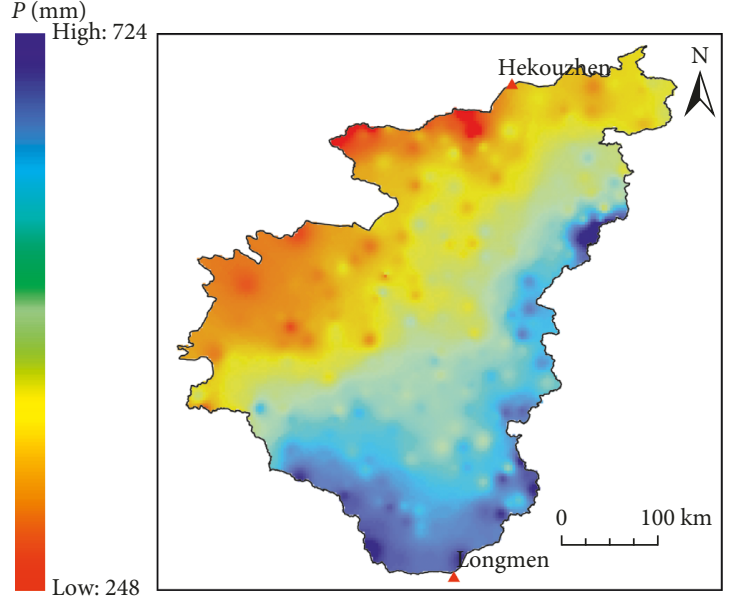

Hydrological station Study area

(a)

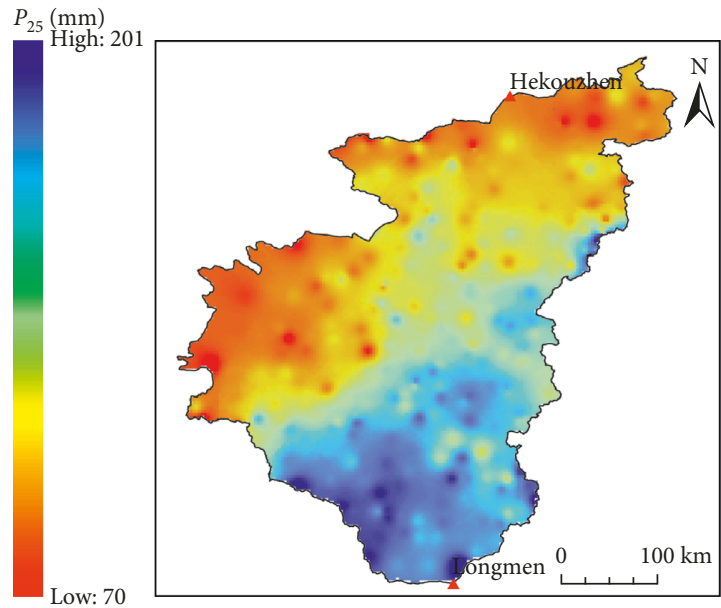

- Hydrological station Study area
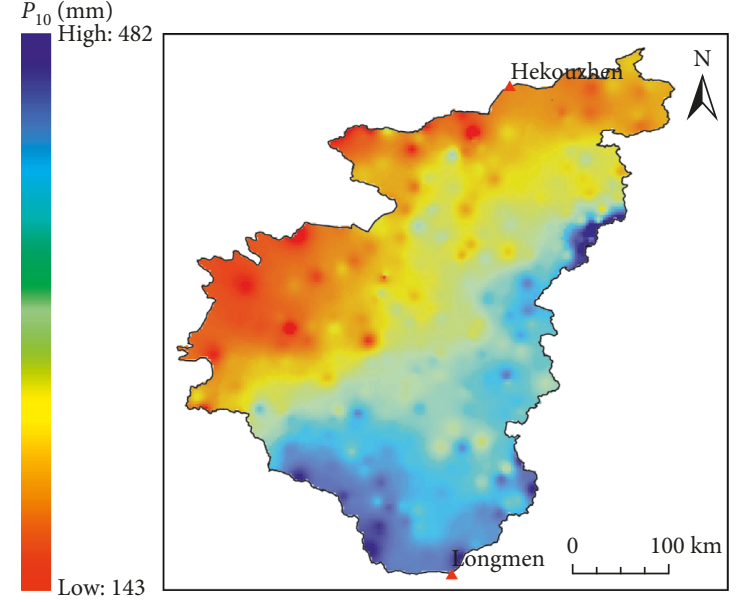

A Hydrological station Study area

(b)

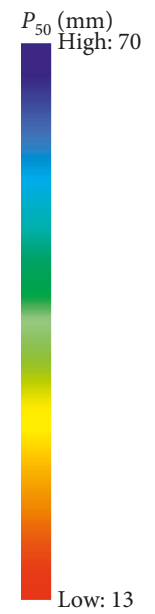

$\Delta$ Hydrological station $\square$ Study area

(d)

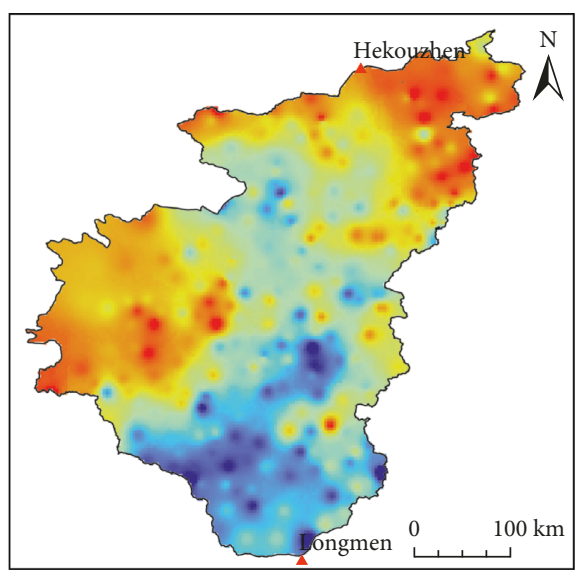

(c)

$P_{100}(\mathrm{~mm})$

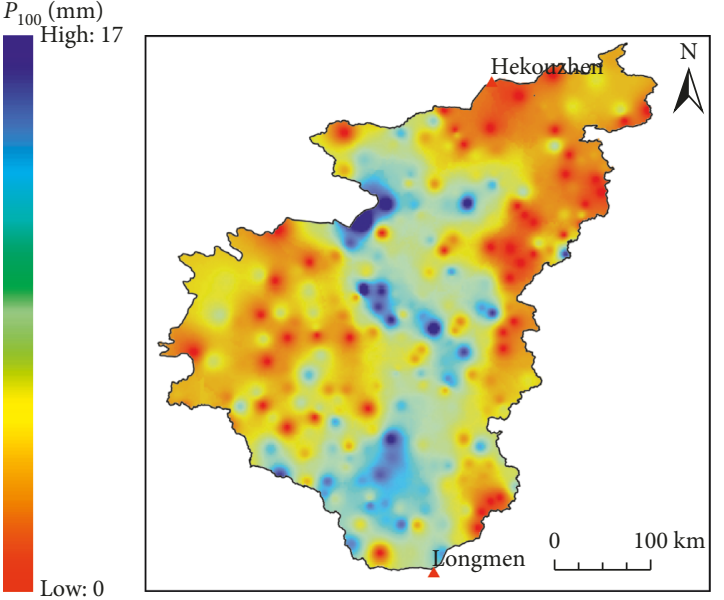

- Hydrological station

Study area

(e)

Figure 2: Spatial distribution of (a) $P$, (b) $P_{10}$, (c) $P_{25}$, (d) $P_{50}$, and (e) $P_{100}$ in the HLR. 


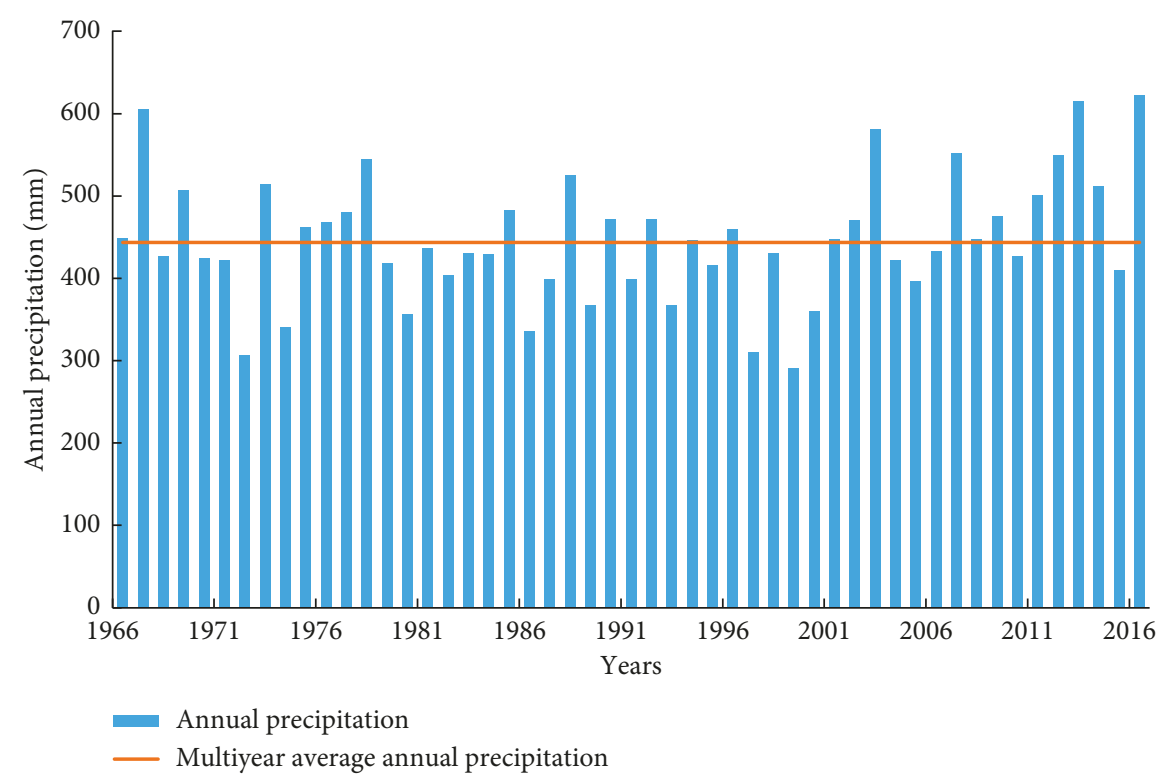

FIgURE 3: Time series of annual precipitation in the HLR from 1966 to 2016.

series from 1966 to 2016, four of the five years with the heaviest rainfall occurred after the year 2000 .

4.1.3. Changes in Different Classes of Precipitation. From 1966 to 2016, the average annual $P_{10}, P_{25}, P_{50}$, and $P_{100}$ values for the HLR were $251.1 \mathrm{~mm}, 128.2 \mathrm{~mm}, 39.1 \mathrm{~mm}$, and $5.4 \mathrm{~mm}$, respectively, accounting for $56.6 \%, 28.9 \%, 8.8 \%$, and $1.2 \%$ of the annual precipitation, respectively (Table 1 ).

Approximately $80 \%-95 \%$ of $P_{10}$ occurred from June to September, and few of these events occurred in May and October. Almost all of the $P_{25}, P_{50}$, and $P_{100}$ events occurred between June and September. The precipitation from June to September in the HLR is mostly characterized by short duration and high rainfall intensity.

The variation in the different classes of precipitation from 1966 to 2016 is shown in Figure 4. It can be seen that, except for $P_{25}$, the different classes of precipitation in 2016 reached the highest observed values since 1966. $P_{25}$ reaches its maximum level in 2013, followed by 2016.

According to the MK test results shown in Table 1, there was no significant trend in annual precipitation, $P_{10}, P_{25}$, $P_{50}$, and $P_{100}$ in the HLR from 1966 to 2016.

4.1.4. Change in Rainstorm Frequency. Figure 5 shows the time series of the frequency of rainstorms and heavy rainstorms from 1966 to 2016 in the HLR. The occurrence of rainstorms and heavy rainstorms was high, and the past 51 years can be divided into three periods. The occurrence of heavy rainstorms in 1982-2000 was obviously lower than normal, and only in 1995 and 1996, a large area of heavy rainfall occurred. Rainstorms and heavy rainstorms occurred frequently in the two periods of 1966-1981 and 2001-2016. Especially in 2007-2016, both the average annual frequency of rainstorms and heavy rainstorms and the proportion of precipitation exceeded the multiyear average values (Table 2).

\subsection{Precipitation Changes in the Focus Period}

4.2.1. Selection of the Focus Period. Since 1998, the rate of change in the sediment-producing environment in the Loess Plateau has been unprecedented $[1,32]$. The turning point in the relationship between rainfall and sediment discharge is an important basis for selecting a focus period.

The double mass curve between rainfall and sediment discharge in the HLR is shown in Figure 6. Based on the change in the slope of the double mass curve of rainfall and sediment discharge, the relationship between rainfall and sediment discharge in the study region obviously changed in 1979 and in 2006, and after 2006, the transition of the relationship between precipitation and sediment discharge was much more significant than the previous turning point.

Since the 1990s, the effects of large-scale soil and water conservation measures have significantly enhanced the reductions in sediment discharge. The relationship between rainfall and sediment discharge has changed significantly and is manifested as the double accumulation points of rainfall and sediment discharge that significantly deviate from the sediment transport axis (Figure 6).

The rainfall-sediment relationship in the major sediment tributaries in the HLR has an inflection point in the 1970s and 1980s [33], but the turning points in 2004-2008 were more prominent than previously observed [1]. Although the annual sediment discharge decreased in the 1970s and the 1980 s, the change in sediment concentration was not significant during the same periods [1]. In fact, until 20042008, the annual sediment discharge, the average sediment concentration during the flood season, and the annual 
TABLE 1: Average precipitation in the HLR from 1966 to 2016.

\begin{tabular}{|c|c|c|c|c|c|}
\hline Rainfall factor & $P$ & $P_{10}$ & $P_{25}$ & $P_{50}$ & $P_{100}$ \\
\hline Precipitation $(\mathrm{mm})$ & 443.6 & 251.1 & 128.2 & 39.1 & 5.4 \\
\hline $\begin{array}{l}\text { Proportion of different precipitation classes of annual } \\
\text { precipitation }(\%)\end{array}$ & - & 56.6 & 28.9 & 8.8 & 1.2 \\
\hline MK $Z$ value & 1.129 & 0.382 & 0.755 & 0.381 & -0.317 \\
\hline
\end{tabular}

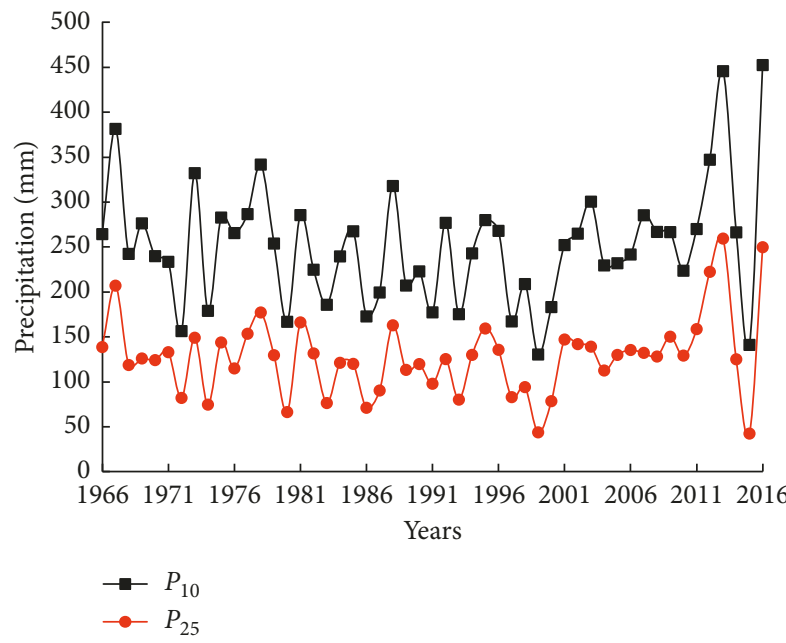

(a)

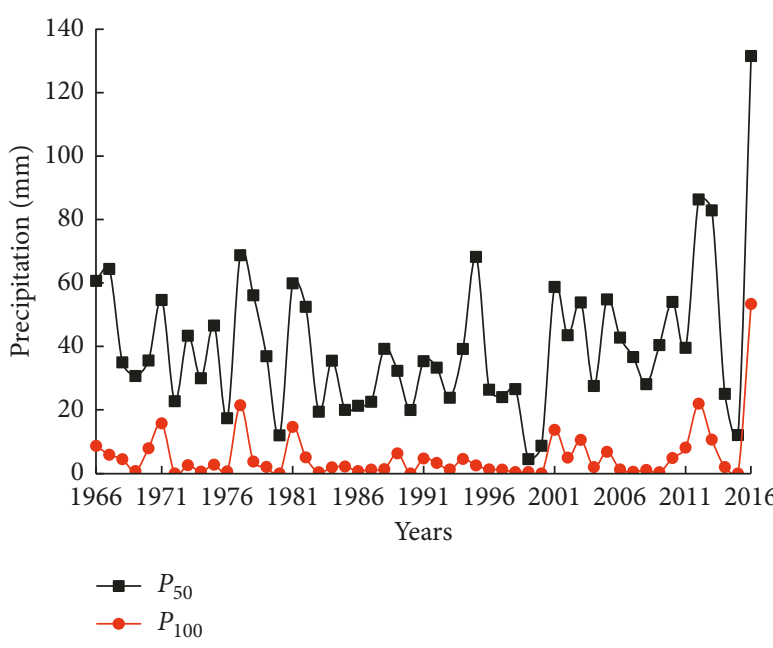

(b)

Figure 4: Time series of different classes of precipitation in the HLR from 1966 to 2016.

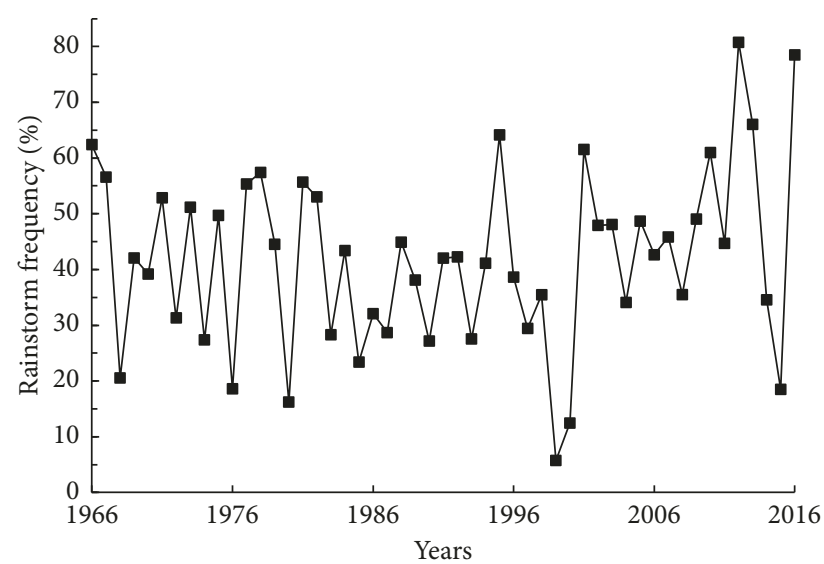

(a)

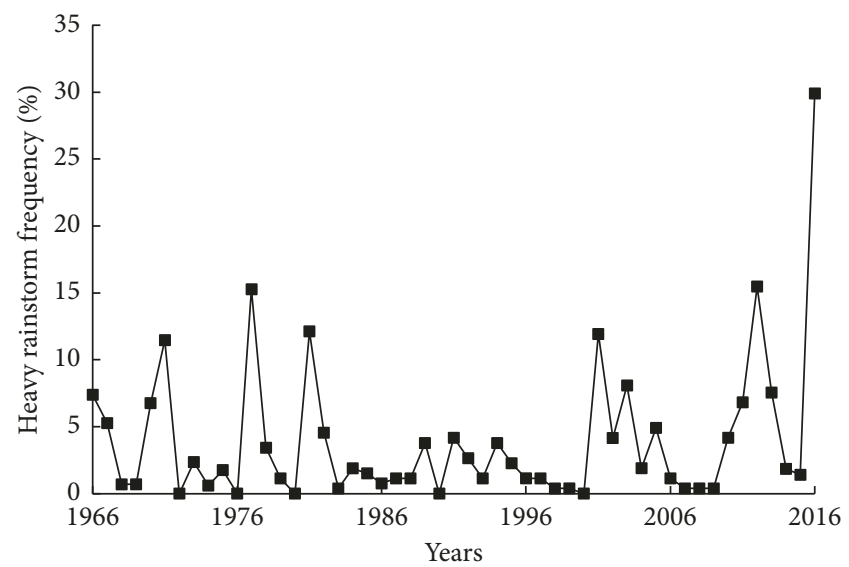

(b)

FIgURE 5: Time series of frequency of rainstorms (a) and heavy rainstorms (b) in the HLR from 1966 to 2016.

TABLE 2: The frequency and rainfall proportion of rainstorms and heavy rainstorms during different periods in the HLR (\%).

\begin{tabular}{lcccc}
\hline \multirow{2}{*}{ Period } & \multicolumn{2}{c}{ Rainstorm } & \multicolumn{2}{c}{ Heavy rainstorm } \\
& Average annual frequency & Rainfall proportion & Average annual frequency & Rainfall proportion \\
\hline $1966-2016$ & 41.9 & 8.8 & 3.41 & 1.2 \\
$2007-2016$ & 51.5 & 10.3 & 6.83 & 2.0 \\
\hline
\end{tabular}




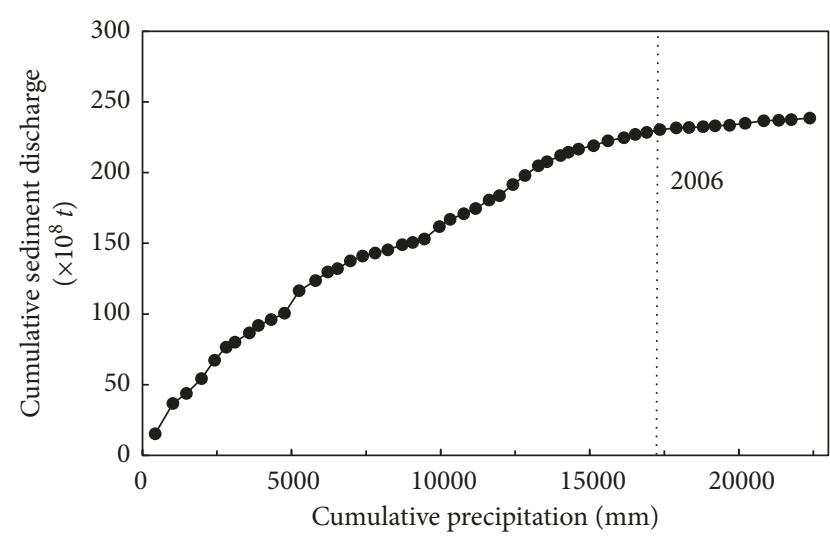

FIgURE 6: The double mass curve between rainfall and sediment discharge in the HLR.

maximum sediment concentration of the major tributaries of the study area decreased considerably $[1,34]$.

Therefore, we selected 2007-2016 as the focus period, emphasizing the analysis of changes in precipitation in the HLR during this period.

4.2.2. Changes in Precipitation from 2007 to 2016. Compared with 1966-2016, the annual precipitation and different classes of precipitation were all generally more abundant during the focus period. In 2007-2016, the average annual precipitation was $507.6 \mathrm{~mm}$, which was $14.4 \%$ higher than the average annual precipitation from 1966 to 2016. Additionally, $P_{10}, P_{25}, P_{50}$, and $P_{100}$ were $20 \%, 26.4 \%, 33.5 \%$, and $90.7 \%$ higher, respectively (Table 3 ), and $P_{100}$ was particularly abundant.

Except for the northern part of the HLR, the different classes of precipitation in the other areas were more abundant (Figure 7). The areas with the most abundant precipitation were mainly located in the central part of the HLR and in the southern part of the region. The area of increasing rainfall intensity was mainly concentrated in the central part of the HLR.

Table 4 shows the proportion of the area with different degrees of change in precipitation from 2007 to 2016 compared with 1966-2016 in the HLR. In most of the study area, the annual precipitation was abundant in 2007-2016, which accounted for $86.58 \%$ of the study area, while the area with the annual precipitation reduction of more than $5 \%$ accounted for $3.56 \%$ of the study area (Table 4). From 2007 to 2016 , the area with $P_{25}, P_{50}$, and $P_{100}$ reduction of more than $5 \%$ accounted for $7.52 \%, 11.4 \%$, and $41.67 \%$ of the study area, respectively (Table 4 ). In contrast, the area where $P_{25}, P_{50}$, and $P_{100}$ were more than $5 \%$ higher accounted for $84.40 \%, 80.11 \%$, and $56.41 \%$ of the study area, respectively.

\subsection{Impacts of Precipitation on Sediment Yield}

4.3.1. Contribution of $P_{50}$ to Sediment Yield. To learn more about the impact of precipitation on sediment yield, the sediment yield of typical tributaries with daily rainfall higher than $50 \mathrm{~mm}$ and the proportion of annual sediment yield in
TABle 3: Changes in precipitation in the HLR from 2007 to 2016.

\begin{tabular}{lcccccccccc}
\hline \multicolumn{4}{c}{$\begin{array}{c}\text { Average precipitation in } \\
\text { 2007-2016 (mm) }\end{array}$} & \multicolumn{1}{c}{ Changes in precipitation (\%) } \\
$P$ & $P_{10}$ & $P_{25}$ & $P_{50}$ & $P_{100}$ & $P$ & $P_{10}$ & $P_{25}$ & $P_{50}$ & $P_{100}$ \\
\hline 507.6 & 301.4 & 162.0 & 52.2 & 10.3 & 14.4 & 20.0 & 26.4 & 33.5 & 90.7 \\
\hline
\end{tabular}

the corresponding year were calculated from 1966 to 1985 (Table 5). The average proportion of sediment yield produced by $P_{50}$ was $50.5 \%$ in the HLR. Compared with Table 1 , although $P_{50}$ accounted for only $8.8 \%$ of the annual precipitation, the amount of sediment yield produced by $P_{50}$ was $50.5 \%$ of the total annual sediment discharge, making $P_{50}$ the key driving force for sediment yield.

The annual sediment yield of $P_{50}$ varied greatly, accounting for $10 \%-98 \%$ of the annual sediment yield in the HLR (Figure 8).

4.3.2. Changes in the Relationship between Rainfall and Sediment Discharge. It has been proposed that $10 \mathrm{~mm}$ of rainfall is the erosive rainfall standard [35], and this value is well correlated with sediment yield [31]. Therefore, $P_{10}$ was selected to analyze the relationship between rainfall and sediment yield in the HLR (Figure 9). Compared with the period before the 1970s, the relationship between rainfall and sediment yield in 2007-2016 experienced great changes. The rainfall-sediment yield relationship in 2007-2016 obviously departed from that before the 1970s, and it is difficult to see the response of sediment yield to rainfall.

4.3.3. Attribution of Changes in Sediment Yield. The hydrological modeling method was employed to estimate the attribution of precipitation and other factors to the changes in sediment yield in the HLR since 1980. The sediment yield reached 936 million tons in the baseline period in the HLR. The hydrological modeling results showed that precipitation led to 225.23, 259.10, 106.30, and -167.79 million ton changes in sediment yield for 1980-1989, 1990-1999, 2000-2009, and 2010-2016, respectively (Table 6). Other factors led to $339.07,202.47,650.03$, and 1017.14 million ton changes in sediment yield for the four periods, respectively (Table 6). Figure 10 shows the relative contributions of precipitation and other factors to the sediment yield changes since 1980. During the period of 1980-1989, the impact of precipitation was responsible for $39.9 \%$ of the sediment yield decrease, while the effects of other factors were responsible for $60.1 \%$ of the sediment yield decrease. Other factors were the main driving factor for the sediment yield changes in the HLR. During the period of 1990-1999, precipitation and other factors were responsible for $56.1 \%$ and $43.9 \%$ of the sediment yield reduction, respectively, which indicated that precipitation was the main driving factor for the sediment yield change. During the period of 2000-2009, precipitation and other factors accounted for $14.1 \%$ and $85.9 \%$ of the sediment yield reduction, respectively. Other factors were obviously the driving factor for the sediment yield reduction. During the period of 2010-2016, precipitation and other factors were responsible for $-19.8 \%$ and $119.8 \%$ of the 


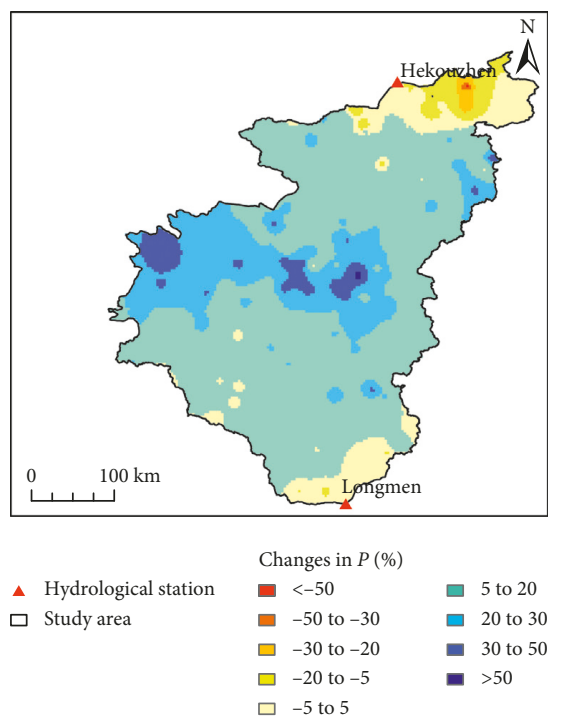

(a)

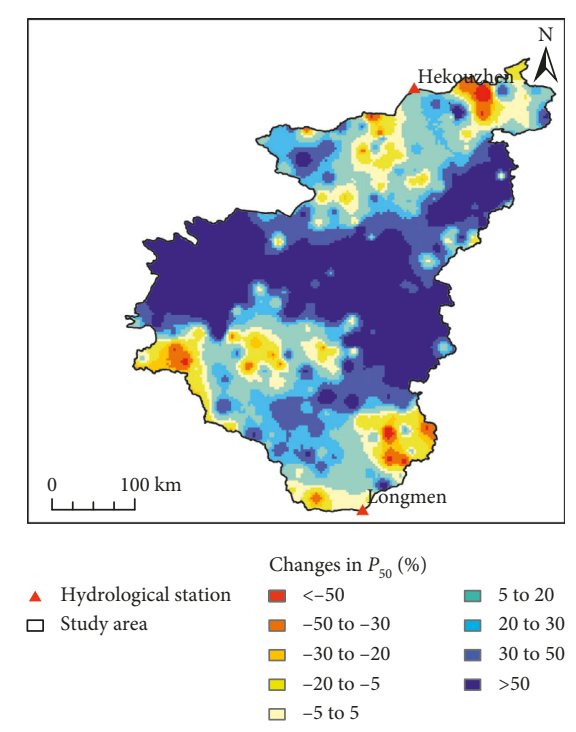

(d)

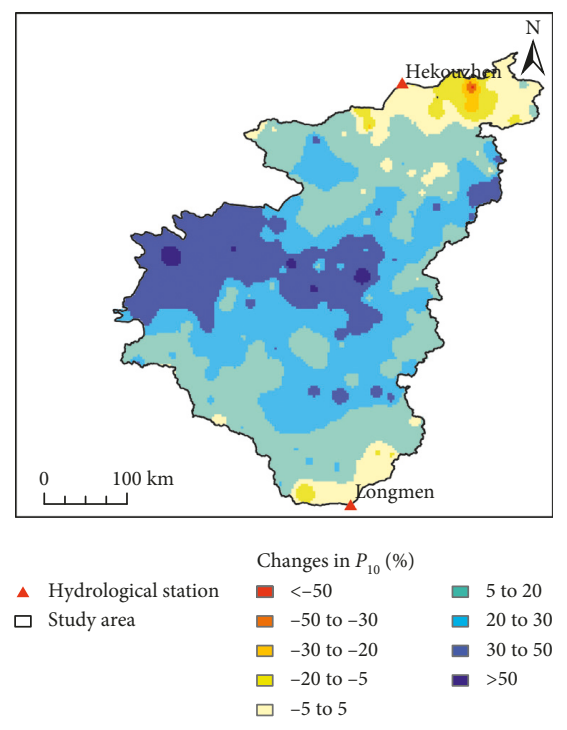

(b)

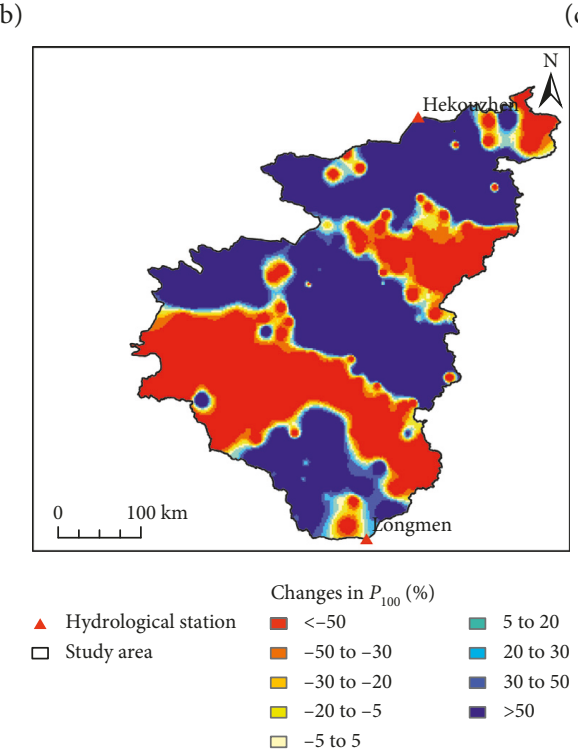

(e)

Figure 7: Spatial distribution of changes in precipitation: (a) $P$, (b) $P_{10}$, (c) $P_{25}$, (d) $P_{50}$, and (e) $P_{100}$, in the HLR from 2007 to 2016 compared with 1966-2016.

sediment yield reduction, respectively. Precipitation increased the sediment yield, while other factors reduced the sediment yield amount and were still the main driving factor for the sediment yield changes.

4.3.4. The Impacts of Precipitation on Sediment Yield in Typical Years. In early July and early August 1977, there were two large-scale and high-intensity rainfall events in the HLR, covering most of the major sediment-yielding areas in the middle reaches of the Yellow River, as shown in Figure 11. Under this rainfall situation, the annual sediment yield of the HLR reached 1.592 billion tons, and the value at the Tongguan station reached 2.21 billion tons in 1977; this was the largest amount of sediment measured since 1968. Therefore, 1977 became a year of great concern to all

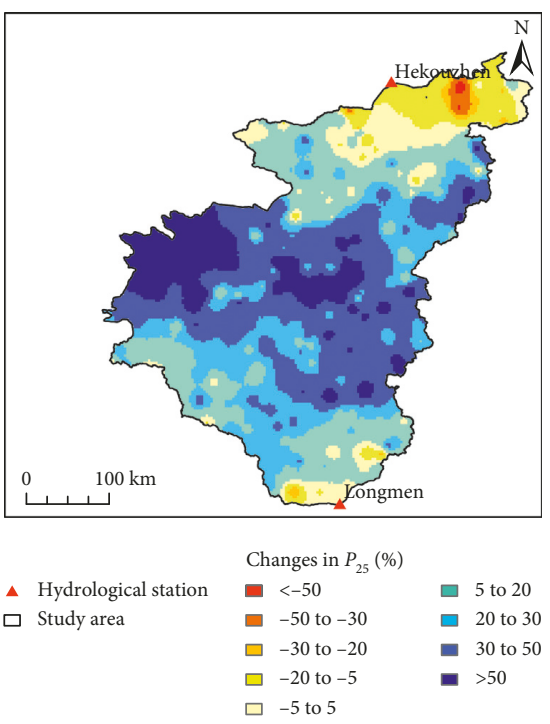

(c) researchers in terms of changes in the water and sediment changes of the Yellow River.

Rainfall in 2012, 2013, and 2016 was relatively abundant in recent years, and their rainstorm covered most of the major sediment-yielding areas in the middle reaches of the Yellow River. Specifically, the heavy rainstorms and rainfall intensities measured in 2016 were the largest from 1966 to 2016 (Figure 11). In 2012 and 2016, high-intensity rainfall events were mainly distributed in the middle and northern parts of the HLR. In 2013, high-intensity rainfall was mainly distributed in the middle and southern parts of the HLR.

In the rainfall situations of 2012, 2013, and 2016, the sediment yield of the HLR reached 142 million tons, 178 million tons, and 108 million tons (Table 7), respectively; additionally, the sediment yield at the Tongguan station 
TABLE 4: The proportion of the area with different degrees of change in precipitation from 2007 to 2016 compared with 1966-2016 in the HLR.

\begin{tabular}{|c|c|c|c|c|c|c|}
\hline \multirow{2}{*}{ Change } & \multirow{2}{*}{ Degree of change } & \multicolumn{5}{|c|}{ Proportion of the area (\%) } \\
\hline & & $P$ & $P_{10}$ & $P_{25}$ & $P_{50}$ & $P_{100}$ \\
\hline \multirow{5}{*}{ Less precipitation } & -5 to $-20 \%$ & 2.99 & 2.64 & 6.00 & 6.87 & 3.18 \\
\hline & -20 to $-30 \%$ & 0.51 & 0.45 & 0.79 & 2.09 & 2.19 \\
\hline & -30 to $-50 \%$ & 0.06 & 0.09 & 0.62 & 2.01 & 5.36 \\
\hline & $>-50 \%$ & 0.00 & 0.00 & 0.11 & 0.43 & 30.95 \\
\hline & Subtotal & 3.56 & 3.18 & 7.52 & 11.40 & 41.67 \\
\hline \multirow{5}{*}{ Abundant precipitation } & 5 to $20 \%$ & 63.57 & 36.14 & 22.16 & 19.01 & 2.98 \\
\hline & 20 to $30 \%$ & 19.54 & 30.83 & 19.90 & 13.37 & 2.05 \\
\hline & 30 to $50 \%$ & 3.43 & 20.06 & 30.22 & 16.09 & 4.26 \\
\hline & $>50 \%$ & 0.04 & 0.68 & 12.12 & 31.64 & 47.13 \\
\hline & Subtotal & 86.58 & 87.71 & 84.40 & 80.11 & 56.41 \\
\hline Slight change & -5 to $5 \%$ & 9.87 & 9.12 & 8.07 & 8.49 & 1.92 \\
\hline
\end{tabular}

TABLE 5: The proportion of sediment yield produced by $P_{50}$ in typical tributaries (\%).

\begin{tabular}{lccccccccc}
\hline Tributary & $\begin{array}{c}\text { Huangpu- } \\
\text { chuan }\end{array}$ & $\begin{array}{c}\text { Gushan- } \\
\text { chuan }\end{array}$ & $\begin{array}{c}\text { Kuye } \\
\text { River }\end{array}$ & $\begin{array}{c}\text { Jialu } \\
\text { River }\end{array}$ & $\begin{array}{c}\text { Yanhe } \\
\text { River }\end{array}$ & $\begin{array}{c}\text { Qingjian } \\
\text { River }\end{array}$ & $\begin{array}{c}\text { Qiushui } \\
\text { River }\end{array}$ & $\begin{array}{c}\text { Xinshui } \\
\text { River }\end{array}$ & $\begin{array}{c}\text { Average weight } \\
\text { of 11 tributaries }\end{array}$ \\
\hline $\begin{array}{l}\text { Proportion of sediment } \\
\text { discharge }\end{array}$ & 52.4 & 36.0 & 66.6 & 32.4 & 42.0 & 33.9 & 42.7 & 66.1 & 50.5 \\
\hline
\end{tabular}

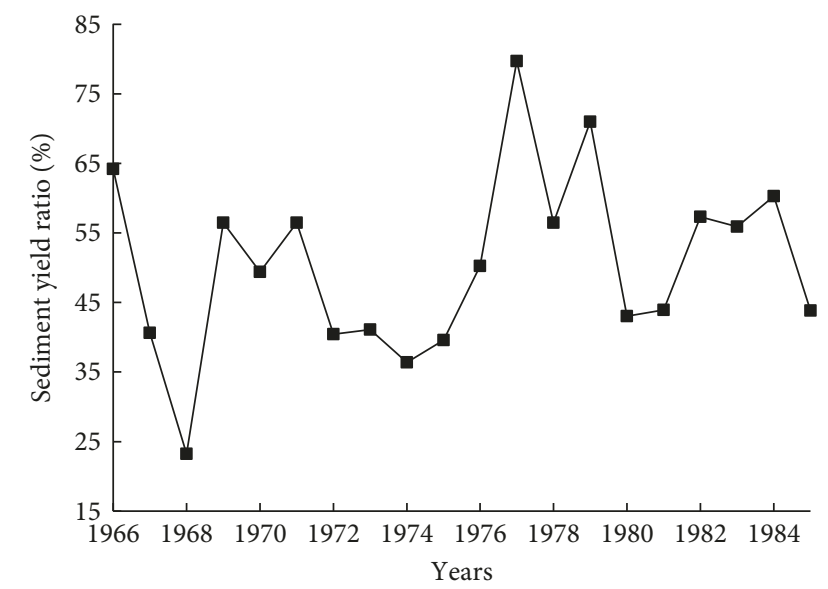

Figure 8: Proportion of sediment produced by $P_{50}$ in the HLR from 1966 to 1985.

reached 206 million tons, 305 million tons, and 108 million tons, respectively.

To better understand the impact of precipitation on sediment yield, $P_{25}, P_{50}$, and $P_{100}$ were calculated for all rainfall stations in 1977, 2012, 2013, and 2016 (Table 7). The results showed that $P_{25}$ and $P_{50}$ were greater in 2012 and 2013 than in 1977, and $P_{100}$ was the same as or lower than the value recorded in 1977; however, the sediment yield of the HLR was $90 \%$ and $89 \%$ lower than the amount recorded in 1977 , respectively. In 2016, $P_{25}, P_{50}$, and $P_{100}$ were all greater than those in 1977, while the sediment yield of the HLR declined by $93 \%$ compared with that in 1977. Through comparative analysis of the precipitation changes in typical years in the HLR, it can be seen that precipitation is not the main cause of sediment yield reduction in recent years, the

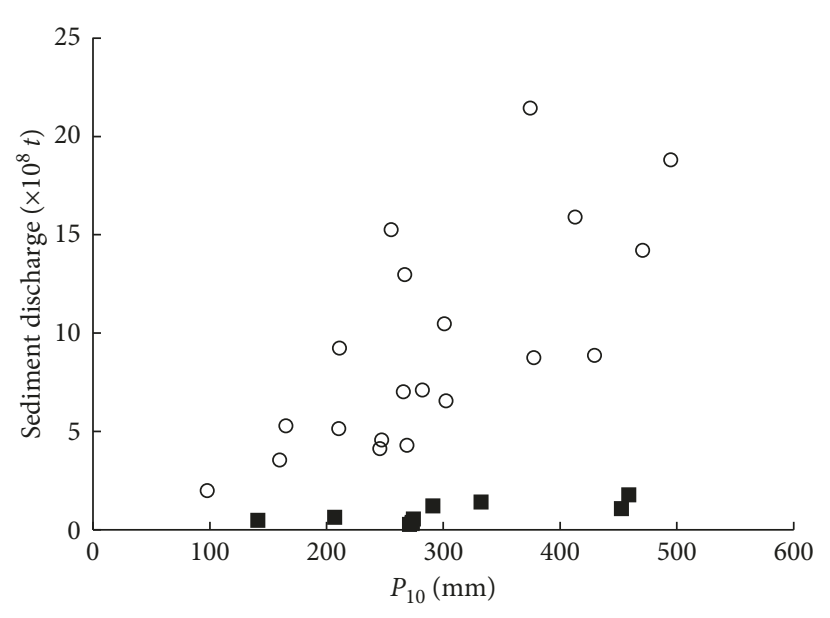

○ $1956-1975$

FIGURE 9: Relationship between rainfall and sediment yield in two periods in the HLR.

current underlying surface has changed a lot compared with the period before 1970s [36], and the sediment yield capacity of most tributaries has decreased significantly [1].

\section{Discussion}

5.1. Comparisons with Similar Studies. Several studies have investigated the spatiotemporal variation in annual precipitation, extreme precipitation, and erosive rainfall in the Loess Plateau or in the middle reaches of the Yellow River Basin in different periods. In this study, we investigated the variations in annual precipitation and different classes of 
TABLe 6: Attribution of the change in sediment yield in the HLR since 1980.

\begin{tabular}{lccccccc}
\hline Period & $W_{\mathrm{S} 1}\left(10^{6} \mathrm{t}\right)$ & $W_{\mathrm{S} 2}\left(10^{6} \mathrm{t}\right)$ & $\Delta W_{\mathrm{S}}\left(10^{6} \mathrm{t}\right)$ & $\Delta W_{\mathrm{SP}}\left(10^{6} \mathrm{t}\right)$ & $\Delta W_{\mathrm{SH}}\left(10^{6} \mathrm{t}\right)$ & $\Delta W_{\mathrm{SP}}(\%)$ & $\Delta W_{\mathrm{SH}}(\%)$ \\
\hline $1980-1989$ & 372.21 & 711.28 & 564.30 & 225.23 & 339.07 & 39.9 & 60.1 \\
$1990-1999$ & 474.93 & 677.40 & 461.58 & 259.10 & 202.47 & 56.1 \\
$2000-2009$ & 180.18 & 830.21 & 756.33 & 106.30 & 650.03 & 14.1 \\
$2010-2016$ & 87.16 & 1104.30 & 849.35 & -167.79 & 1017.14 & -19.8 & 119.8 \\
\hline
\end{tabular}

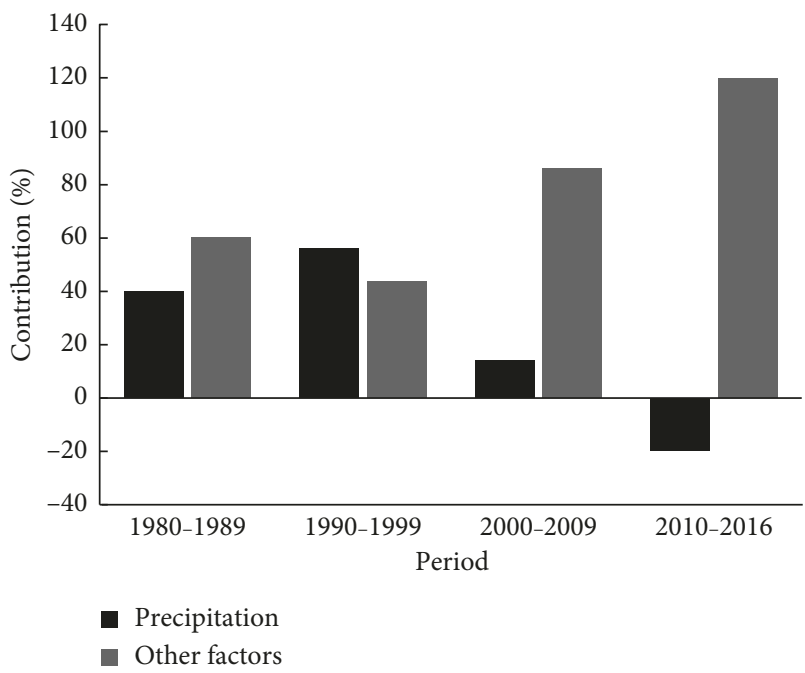

FIGURE 10: Contributions of precipitation and other factors to the changes in sediment yield in the HLR since 1980.

precipitation using high-resolution data, which provided more detailed information than other studies.

In general, annual precipitation exhibited no obvious trend in the Loess Plateau for the last decades. For example, Sun et al. and Zhang et al. found that the annual total precipitation showed no obvious trends in the Loess Plateau and in the middle reaches of the Yellow River Basin during 1960-2013 [37, 38], respectively; Wang et al. suggested that the region-averaged annual precipitation shows a nonsignificant negative trend in the Loess Plateau in the period of 1961-2010 [39], which all agree with the results of our study.

Besides, the results reported by Sun et al. and Xin et al. were not completely consistent with the conclusions of our study $[8,40]$. Xin et al. suggested that the annual rainfall and erosive rainfall decreased in the Loess Plateau from 1956 to 2008 [40]. Sun et al. found that the total amount of precipitation on wet days decreased over a large area of the Loess Plateau during 1961-2011, particularly in the southeast region [8]. The differences between our findings and those reported by Xin et al. and Sun et al. are probably related to the different research periods and spatial domains adopted by these studies. The decreasing trends were mainly due to the relatively dry period in the 2000s in the Loess Plateau. In this study, we found different trends using updated time series, and the precipitation data extended into 2016. According to Figures 3 and 4, annual precipitation and different classes of precipitation had increased in the last several years (2012-2016). This was due to increased precipitation and more frequent storms occurring in recent years in the HLR. Zhao et al. has found the similar pattern for extreme precipitation indices [41].

5.2. Changes in the Underlying Surface. The sediment yield reduction caused by other factors is the total amount of sediment reduction produced by the changes in the underlying surface in the HLR. Vegetation changes, terraces, check dams, reservoirs, irrigation, and channel scouring and siltation are the main underlying surface factors in the study area. Since the late 1970s, numerous soil conservation practices have been implemented in the Loess Plateau (Tables 8 and 9), such as afforestation and construction of level terraces and check dams, to reduce soil erosion [42, 43]. Some studies indicated that sediment yield reduction in major tributaries in the middle reaches of the Yellow River Basin was mainly caused by the SCP [44, 45], which can effectively reduce the sediment yield by increasing intercepted precipitation and water infiltration, retarding surface runoff and trapping sediment $[46,47]$.

With the implementation of the nationwide ecological recovery program (i.e., the "Grain for Green Project" (GGP)) since 1999, the vegetation coverage in the HLR has greatly increased [48]. The major factors impacting the effects of vegetation on sediment reduction are the vegetation coverage and thickness of litter layer and plant roots $[49,50]$. When the percentage of effective vegetation is less than $35 \sim 40 \%$, vegetation improvement has an obvious impact on reducing sediment [16]. Regardless of precipitation, vegetation type, and other underlying surface factors, surface erosion is extremely weak when the vegetation coverage is greater than $70 \%$ [51]. At the end of the twentieth century, the vegetation coverage in the HLR was mostly 12 30\% [16]. With the implementation of GGP, the vegetation coverage in many areas of the HLR in 2010 has reached 40 60\% [16], which has exactly experienced the sensitive period of vegetation change and sediment yield response. The results of turning point detection further reveal that abrupt changes likely have associations with the implementation of SCP and GGP (Figure 6). Different types of underlying surface factors had different influences on the sediment yield changes. The proportional effect of different underlying surface factors on sediment yield changes should be further investigated.

With the continuous increase of vegetation coverage, the check dam would be damaged during heavy rains, and the reservoirs and check dams will be gradually filled up and lose the function of sediment retention; the future change trend of sediment yield in the Yellow River Basin still should be further investigated. 


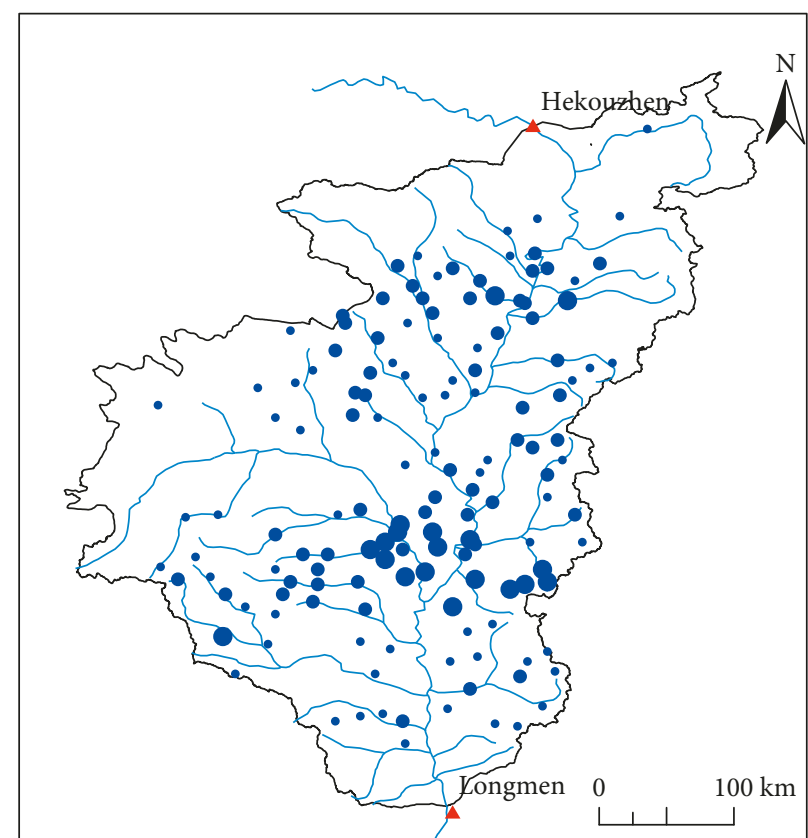

$P_{50}(\mathrm{~mm})$

- Hydrological station

- River

Study area

- 50-100

- $100-200$

- $200-400$

(a)

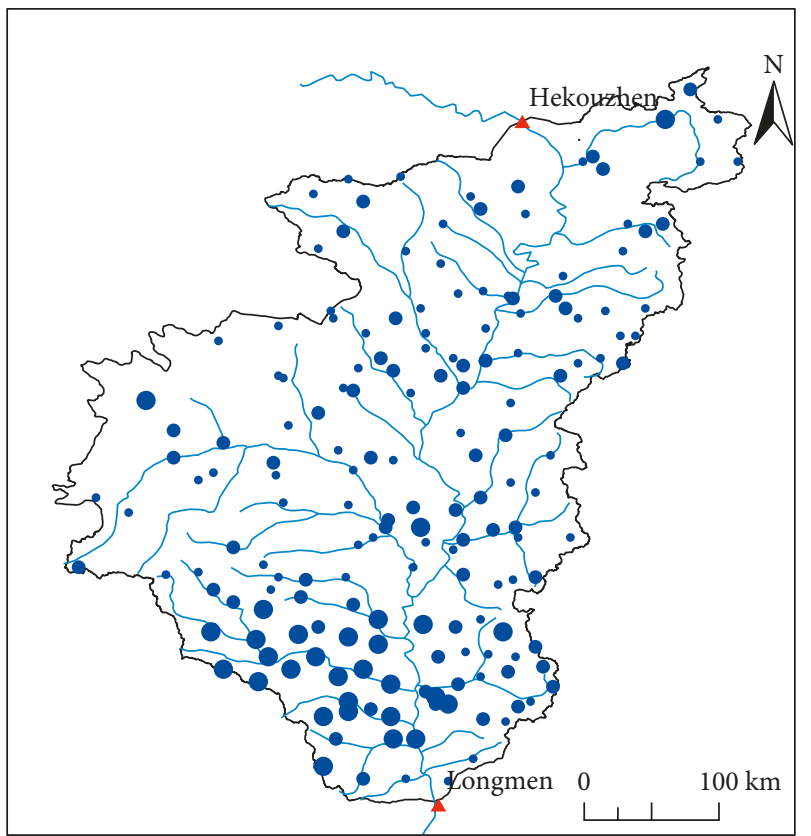

$P_{50}(\mathrm{~mm})$

$\Delta \quad$ Hydrological station
$-\quad$ River
$\square$ Study area

- 50-100

- $100-200$

- $200-400$

(c)

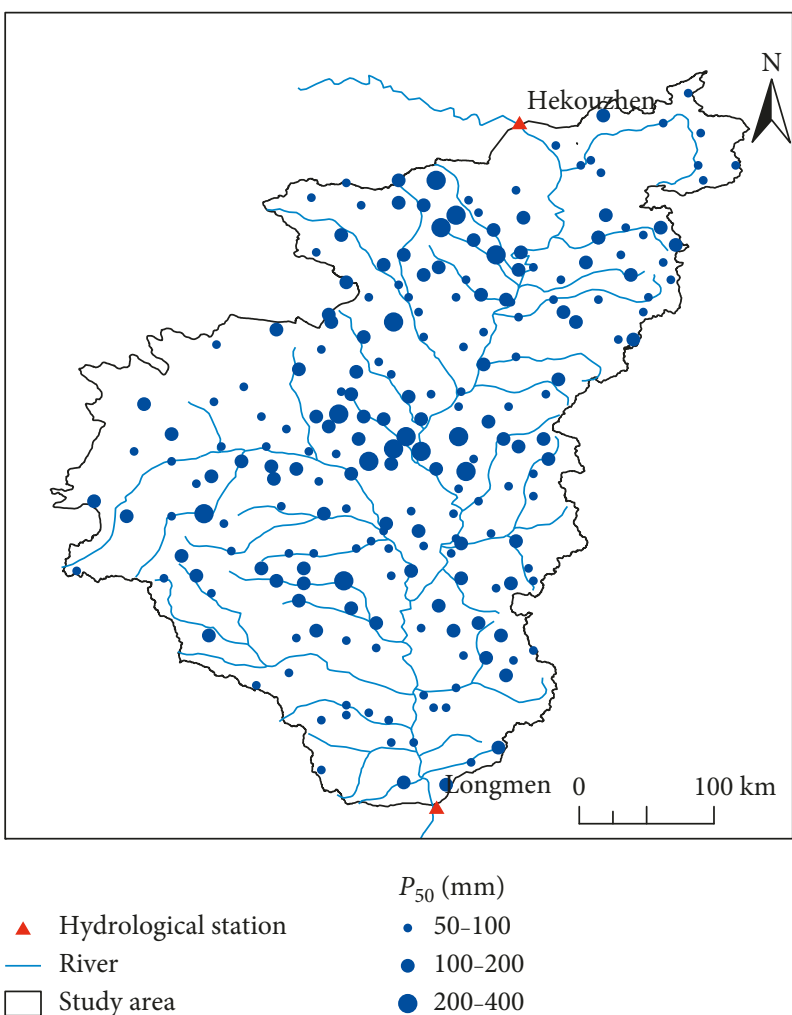

(b)

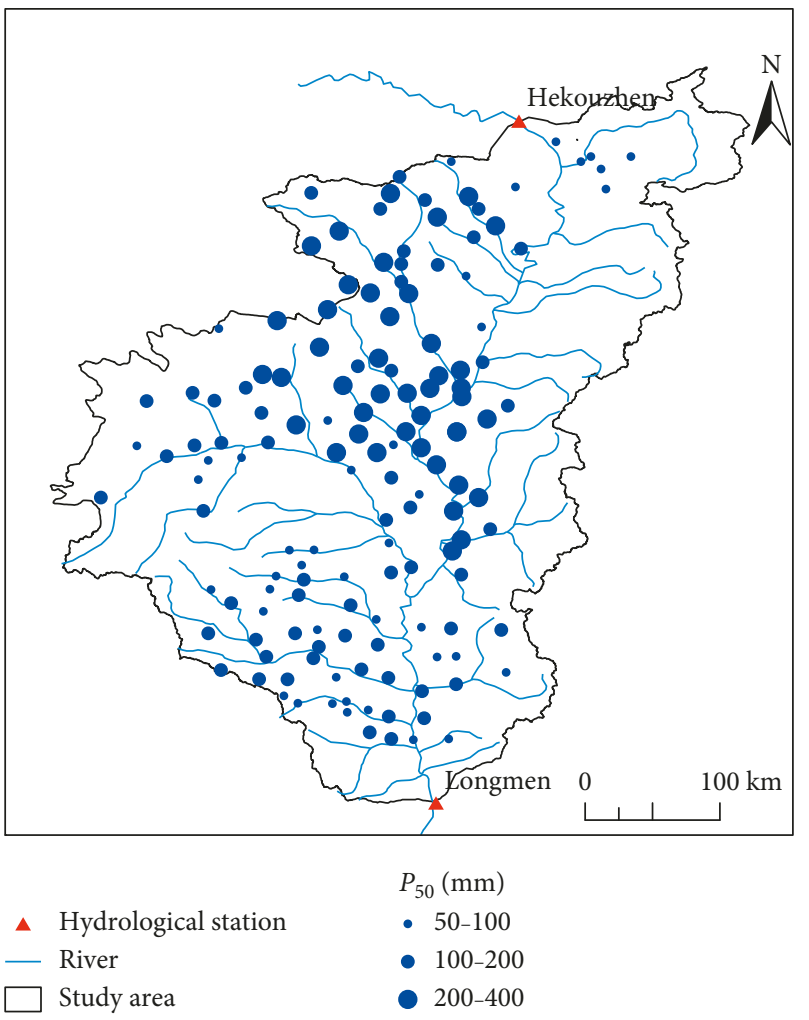

(d)

FIGURE 11: Spatial distribution of rainstorms in typical years: (a) 1977, (b) 2012, (c) 2013, and (d) 2016, in the HLR. 
TABLE 7: Comparison of precipitation over the heavy rainfall events and the sediment yield of the HLR in typical years.

\begin{tabular}{lcccc}
\hline Year & $P_{25}(\mathrm{~mm})$ & $P_{50}(\mathrm{~mm})$ & $P_{100}(\mathrm{~mm})$ & $S^{*}(\mathrm{million}$ tons $)$ \\
\hline 1977 & 160 & 71.0 & 22.4 & 1592 \\
2012 & 222.4 & 85.6 & 22.3 & 142 \\
2013 & 268.6 & 86.8 & 12.2 & 178 \\
2016 & 241.7 & 125.1 & 42.8 & 108 \\
\hline
\end{tabular}

${ }^{*} S$ represents the sediment yield of the HLR.

TABLE 8: Quantity of soil conservation practices by 2011 in the HLR.

\begin{tabular}{lcccc}
\hline \multicolumn{1}{c}{ Soil conservation practices } & Quantity & Total storage capacity $\left(10^{8} \mathrm{~m}^{3}\right)$ & 14.0 & $\mathrm{Area}^{\left(\mathrm{km}^{2}\right)}$ \\
\hline \multirow{2}{*}{ Reservoir } & Large reservoir & 4 & 19.24 & - \\
& Medium-sized reservoir & 44 & 4.01 & - \\
Check dam & Small-sized reservoir & 102 & 40.097 & - \\
Level terrace & Key check dam & 3726 & - & 4716.5 \\
\hline
\end{tabular}

TABLe 9: Statistics of the quantity of key check dams built in each decade in the HLR.

\begin{tabular}{lcccccc}
\hline Decades & $1950-1959$ & $1960-1969$ & $1970-1979$ & $1980-1989$ & $1990-1999$ & $2000-2011$ \\
\hline Quantity & 73 & 261 & 1052 & 247 & 488 & 1605 \\
\hline
\end{tabular}

\section{Conclusions}

In this study, based on the daily precipitation data collected at 301 rainfall stations in the HLR from 1966 to 2016, we investigated the spatial and temporal variations of annual precipitation and different classes of precipitation, and the impacts of precipitation on sediment yield were investigated. The main conclusions can be summarized as follows.

Spatially, the annual precipitation and $P_{10}$ increased gradually from the northwest to the southeast of the HLR, and $P_{25}$ and $P_{50}$ were mainly concentrated in the northwestern and southwestern parts of the HLR, suggesting that it was drier in the northwest region than the southeast region of the HLR, and heavy rain was more likely to occur in the northwest and southwest regions of the HLR. There was no significant trend in annual precipitation, $P_{10}, P_{25}, P_{50}$, and $P_{100}$ in the HLR from 1966 to 2016.

Compared with the multiyear average precipitation from 1966 to 2016 , the annual precipitation, $P_{10}, P_{25}, P_{50}$, and $P_{100}$ in the HLR in the period of 2007-2016 were $14.4 \%, 20 \%$, $26.4 \%, 33.5 \%$, and $90.7 \%$ higher, respectively. The area where $P_{25}, P_{50}$, and $P_{100}$ were more than $5 \%$ higher accounted for $84.40 \%, 80.11 \%$, and $56.41 \%$ of the study area, respectively. The area with $P_{25}, P_{50}$, and $P_{100}$ reduction of more than $5 \%$ accounted for $7.52 \%, 11.4 \%$, and $41.67 \%$, respectively. The occurrence frequency of rainstorms and heavy rainstorms was also higher in the period of 2007-2016 in the HLR.

The relationship between rainfall and sediment yield during 2007-2016 has changed compared with the period before the 1970s, and the analysis of the impacts of precipitation on sediment yield in typical years showed that precipitation is not the main cause of sediment yield reduction in recent years. The hydrological modeling method was used to quantitatively assess the attribution of precipitation and other factors to sediment yield changes in the HLR since 1980. The results showed that precipitation was the main driving factor for the sediment yield change during the period of 1990-1999, which accounted for $56.1 \%$ of the sediment yield reduction. Other factors were the main driving factor for the sediment yield change in the periods of 1980-1989, 2000-2009, and 2010-2016 and were responsible for $60.1 \%, 85.9 \%$, and $119.8 \%$ of the sediment yield decrease, respectively, and other factors were playing a bigger role in the sediment yield change.

This study provided a comprehensive understanding of the variation in precipitation in the HLR and highlighted its effect on sediment yield. The precipitation in the HLR has been more abundant in recent years, although this increase does not explain the significant reduction in sediment yield. Further investigation is required to assess the impacts of underlying surface changes, especially vegetation restoration, on the sediment yield of the Yellow River. This study area is one of the main source areas for the sediment in the Yellow River Basin, and our results are helpful for understanding the cause of the significant reduction in sediment yield observed in recent years.

\section{Data Availability}

The data used to support the findings of this study may be released upon application to the Hydrology Bureau of Yellow River Conservancy Commission, who can be contacted at http://www.hwswj.gov.cn/.

\section{Conflicts of Interest}

The authors declare that they have no conflicts of interest.

\section{Acknowledgments}

This research was supported by the National Key R\&D Program of China (2016YFC0402400 and 2017YFC0403600) 
and the National Natural Science Foundation of China (41301030).

\section{References}

[1] X. Liu, Causes of Sharp Reduction of Runoff and Sediment in the Yellow River in Recent Years, Science China Press, Beijing, China, 2016, in Chinese.

[2] X. Jiongxin, Influence of Soil and Water Conservancy Projects on Flood and Sediment in the Hekouzhen to Longmen Region of the Middle Yellow River, Zhengzhou: The Yellow River Water Consercancy Press, Zhengzhou, China, 2009, in Chinese.

[3] G. Wang, Yellow River Flood, Zhengzhou: The Yellow River Water Conservancy Press, Zhengzhou, China, 1997.

[4] L. Kang, Y. Wang, G. Wang et al., "Analysis of rainfall distribution and the variation features in the region of Hekouzhen to Longmen in the middle Yellow River," Yellow River, vol. 21, no. 8, pp. 3-5, 1999, in Chinese.

[5] C. Hu, Y. Wang, Y. Zhang et al., "Variating tendency of runoff and sediment load in China major river and its causes," Advances in Water Science, vol. 21, no. 4, pp. 524-532, 2010, in Chinese.

[6] W. Yao, D. Ran, and J. Chen, "Recent changes in runoff and sediment regimes and future projections in the Yellow River basin," Advances in Water Science, vol. 24, no. 5, pp. 607-616, 2013, in Chinese.

[7] L. Luo, Z. J. Wang, X. Y. Liu et al., "Changes in characteristics of precipitation in flood season over five typical basins of middle reaches of the Yellow River in China," Journal of Hydraulic Engineering, vol. 44, no. 7, pp. 848-855, 2013, in Chinese.

[8] Q. Sun, C. Miao, Q. Duan et al., "Temperature and precipitation changes over the Loess Plateau between 1961 and 2011, based on high-density gauge observations," Global and Planetary Change, vol. 132, no. 1, pp. 1-10, 2015.

[9] G. Fu, S. Chen, C. Liu, and D. Shepard, "Hydro-climatic trends of the Yellow River basin for the last 50 years," Climatic Change, vol. 65, no. 1-2, pp. 149-178, 2004.

[10] Q. Zhang, J. Peng, V. P. Singh, J. Li, and Y. D. Chen, "Spatiotemporal variations of precipitation in arid and semiarid regions of China: the Yellow River basin as a case study," Global and Planetary Change, vol. 114, no. 2, pp. 38-49, 2014.

[11] F. Yuan, H. Yasuda, R. Berndtsson et al., "Regional sea-surface temperatures explain spatial and temporal variation of summer precipitation in the source region of the Yellow River," Hydrological Sciences Journal, vol. 61, no. 8, pp. 1383-1394, 2015.

[12] Y. He, X. Mu, P. Gao et al., "Spatial variability and periodicity of precipitation in the middle reaches of the Yellow River, China," Advances in Meteorology, vol. 2016, Article ID 9451614, 9 pages, 2016.

[13] F. F. Zhao, Z. X. Xu, J. X. Huang, and J. Y. Li, "Monotonic trend and abrupt changes for major climate variables in the headwater catchment of the Yellow River basin," Hydrological Processes, vol. 22, no. 23, pp. 4587-4599, 2010.

[14] E. Li, X. Mu, G. Zhao, P. Gao, and H. Shao, "Variation of runoff and precipitation in the Hekou-Longmen region of the Yellow River based on elasticity analysis," Scientific World Journal, no. 1, Article ID 929858, 11 pages, 2014.

[15] Y. He, P. Tian, X. Mu et al., "Changes in daily and monthly rainfall in the middle Yellow River, China," Theoretical and Applied Climatology, vol. 129, no. 1, pp. 1-2, 2016.

[16] X. Liu, S. Yang, S. Dang, Y. Luo, X. Y. Li, and X. Zhou, "Response of sediment yield to vegetation restoration at a large spatial scale in the Loess Plateau," Science China Technological Sciences, vol. 57, no. 8, pp. 1482-1489, 2014.

[17] J. Searcy and C. Hardison, Double-Mass Curves, U.S. Geological Survey Water Supply Paper.1541-B, Washington, DC, USA, 1960.

[18] J. M. Albert, "Hydraulic analysis and double mass curves of the Middle Rio Grande from Cochiti to San Marcial," M.S. thesis, Colorado State University, Fort Collins, CO, USA, 2004.

[19] X. Mu, X. Zhang, P. Gao et al., "Theory of double mass curve and its applications in hydrology and meteorology," Journal of China Hydrology, vol. 30, no. 4, pp. 47-51, 2010, in Chinese.

[20] D. Ran, B. Liu, L. Fu et al., "Methods of double mass curve calculation of effectiveness of water and sediment reduction of soil and water conservation measures," Yellow River, no. 6, pp. 24-25, 1996, in Chinese.

[21] X. Mu, C. Basang, and Z. Lu, "Impact of soil conservation measures on runoff and sediment in Hekou-Longmen region of the Yellow River," Journal of Sediment Research, no. 2, pp. 36-41, 2007, in Chinese.

[22] D. Zhang, H. Hong, Q. Zhang et al., "Attribution of the changes in annual streamflow in the Yangtze River Basin over the past 146 years," Theoretical and Applied Climatology, vol. 119, no. 1-2, pp. 323-332, 2015.

[23] H. B. Mann, "Nonparametric tests against trend," Econometrica, vol. 13, no. 3, pp. 245-259, 1945.

[24] M. G. Kendall, Rank Correlation Methods, Griffin, London, UK, 1955.

[25] J. M. Mitchell, B. Dzerdzeevskii, and H. Flohn, Climate Change, World Meteorological Organization, Geneva, Switzerland, 1966.

[26] C. Liu and J. Xia, "Water problems and hydrological research in the Yellow River and the huai and hai river basins of China," Hydrological Processes, vol. 18, no. 12, pp. 2197-2210, 2004.

[27] H. Zheng, Z. Lu, R. Zhu, C. Liu, Y. Sato, and Y. Fukushima, "Responses of streamflow to climate and land surface change in the headwaters of the Yellow River Basin," Water Resources Research, vol. 45, no. 7, pp. 641-648, 2009.

[28] M. Saifullah, Z. Li, Q. Li, M. Zaman, and S. Hashim, "Quantitative estimation of the impact of precipitation and land surface change on hydrological processes through statistical modeling," Advances in Meteorology, vol. 2016, Article ID 6130179, 15 pages, 2016.

[29] G. Zhao, G. Hörmann, N. Fohrer, Z. Zhang, and J. Zhai, "Streamflow trends and climate variability impacts in poyang lake basin, China," Water Resources Management, vol. 24, no. 4, pp. 689-706, 2010.

[30] Y. Chen, Y. Guan, G. Shao, and D. Zhang, "Investigating trends in streamflow and precipitation in huangfuchuan basin with wavelet analysis and the mann-kendall test," Water, vol. 8, no. 3, p. 77, 2016.

[31] X. Li, X. Liu, and Z. Li, "Effects of rainfall and underlying surface on sediment yield in the main sediment-yielding area of the Yellow River," Journal of Hydraulic Engineering, vol. 47, no. 10, pp. 1253-1259, 2016, in Chinese.

[32] C. Jiang, F. Wang, H. Zhang et al., "Quantifying changes in multiple ecosystem services during 2000-2012 on the Loess Plateau, China, as a result of climate variability and ecological restoration," Ecological Engineering, vol. 97, pp. 258-271, 2016.

[33] X. Yue, X. Mu, G. Zhao, H. Shao, and P. Gao, "Dynamic changes of sediment load in the middle reaches of the Yellow River basin, China and implications for eco-restoration," Ecological Engineering, vol. 73, pp. 64-72, 2014. 
[34] Q. Yan, T. Lei, C. Yuan et al., "Effects of watershed management practices on the relationships among rainfall, runoff, and sediment delivery in the hilly-gully region of the Loess Plateau in China," Geomorphology, vol. 228, pp. 735-745, 2015.

[35] W. Wang, "Study on the relations between rainfall characteristics and loss of soil in loess region," Bulletin of Soil and Water Conservation, vol. 3, no. 4, pp. 7-13, 1983, in Chinese.

[36] P. Bai, X. Liu, K. Liang, and C. Liu, "Investigation of changes in the annual maximum flood in the Yellow River basin, China," Quaternary International, vol. 392, pp. 168-177, 2016.

[37] W. Sun, X. Mu, X. Song, D. Wu, A. Cheng, and B. Qiu, "Changes in extreme temperature and precipitation events in the Loess Plateau (China) during 1960-2013 under global warming," Atmospheric Research, vol. 168, no. 22, pp. 33-48, 2016.

[38] Y. Zhang, J. Xia, and D. She, "Spatiotemporal variation and statistical characteristic of extreme precipitation in the middle reaches of the Yellow River Basin during 1960-2013," Theoretical and Applied Climatology, no. 15, pp. 1-18, 2018.

[39] Q. X. Wang, X. H. Fan, Z. D. Qin et al., "Change trends of temperature and precipitation in the Loess Plateau region of China, 1961-2010," Global and Planetary Change, vol. 92-93, pp. 138-147, 2012.

[40] Z. Xin, X. Yu, Q. Li, and X. X. Lu, "Spatiotemporal variation in rainfall erosivity on the Chinese Loess Plateau during the period 1956-2008," Regional Environmental Change, vol. 11, no. 1, pp. 149-159, 2011.

[41] G. Zhao, J. Zhai, P. Tian et al., "Variations in extreme precipitation on the Loess Plateau using a high-resolution dataset and their linkages with atmospheric circulation indices," Theoretical and Applied Climatology, vol. 133, no. 3-4, pp. 1235-1247, 2017.

[42] X. Zhang, L. Zhang, J. Zhao, P. Rustomji, and P. Hairsine, "Responses of streamflow to changes in climate and land use/ cover in the Loess Plateau, China," Water Resources Research, vol. 44 , no. 7 , pp. $2183-2188,2008$.

[43] G. Li and L. Sheng, "Model of water-sediment regulation in Yellow River and its effect," Science China Technological Sciences, vol. 54, no. 4, pp. 924-930, 2011.

[44] Z. Xu and J. Chen, "Analysis of soil and water conservation treatments on runoff in the Middle Yellow River," Yellow River, vol. 25, no. 7, pp. 125-129, 2010, in Chinese.

[45] D. Ran, Q. Luo, B. Liu et al., "Effect of soil-retaining dams on flood and sediment reduction in the middle reaches of the Yellow River," Journal of Hydraulic Engineering, vol. 35, no. 5, pp. 7-13, 2004, in Chinese.

[46] M. Huang and L. Zhang, "Hydrological responses to conservation practices in a catchment of the Loess Plateau, China," Hydrological Processes, vol. 18, no. 10, pp. 1885-1898, 2004.

[47] C. Miao, J. Ni, A. G. L. Borthwick, and L. Yang, "A preliminary estimate of human and natural contributions to the changes in water discharge and sediment load in the Yellow River," Global and Planetary Change, vol. 76, no. 3-4, pp. 196-205, 2011.

[48] Y. Luo, S. Yang, X. Liu et al., "Land use change in the reach from Hekouzhen to Tongguan of the Yellow River during 1998-2010," Acta Geographica Sinica, vol. 69, no. 1, pp. 42-53, 2014.

[49] K. Tang, China Water and Soil Conservation, Science China Press, Beijing, China, 2003, in Chinese.
[50] Q. Meng, Water and Soil Conservation in Loess Plateau, Yellow River Water Conservancy Press, Zhengzhou, China, 1996, in Chinese.

[51] K. Jing, W. Wang, and F. Zheng, Chinese Soil Erosion and Environment, Science China Press, Beijing, China, 2005, in Chinese. 

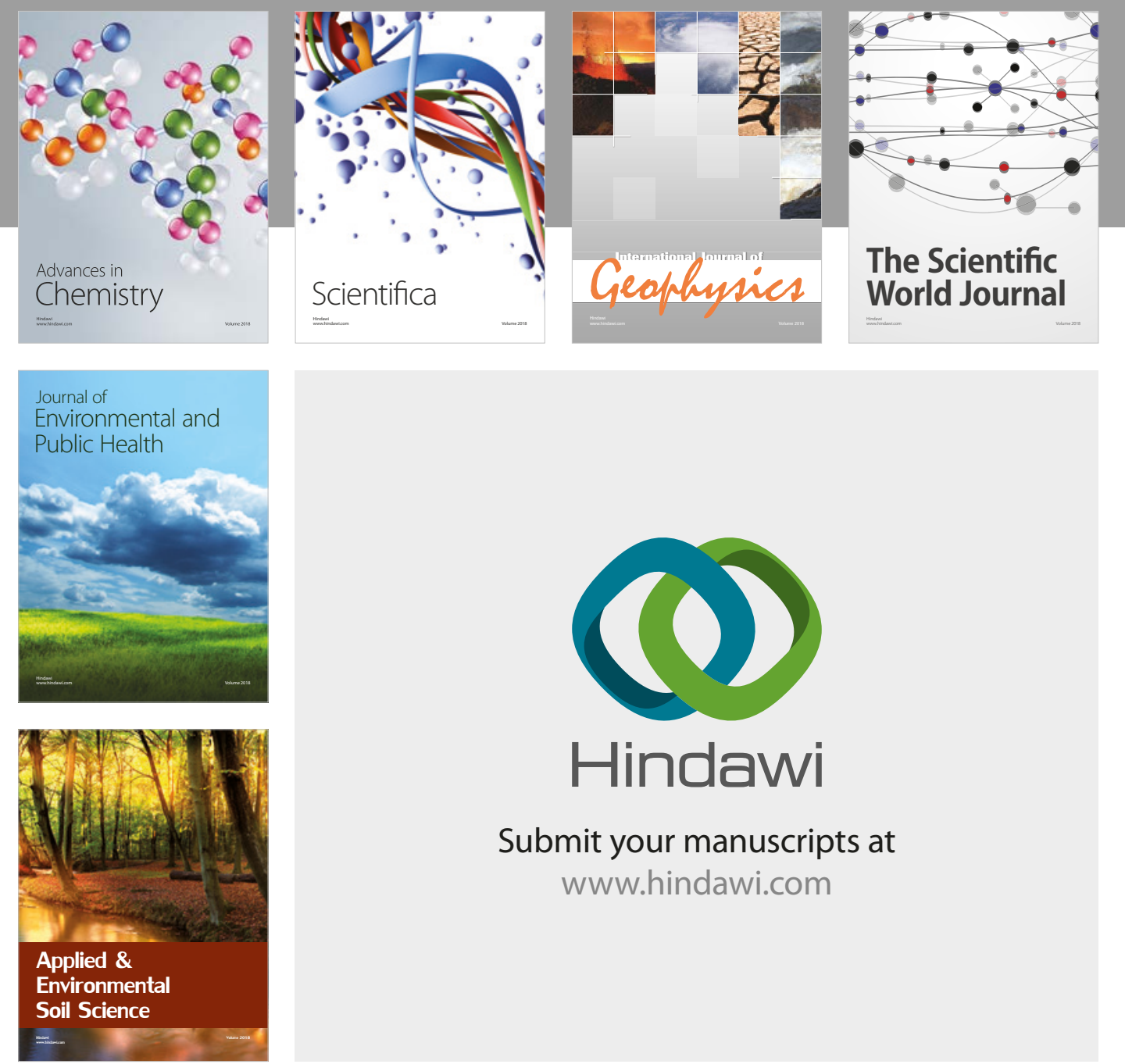

The Scientific

\section{World Journal}
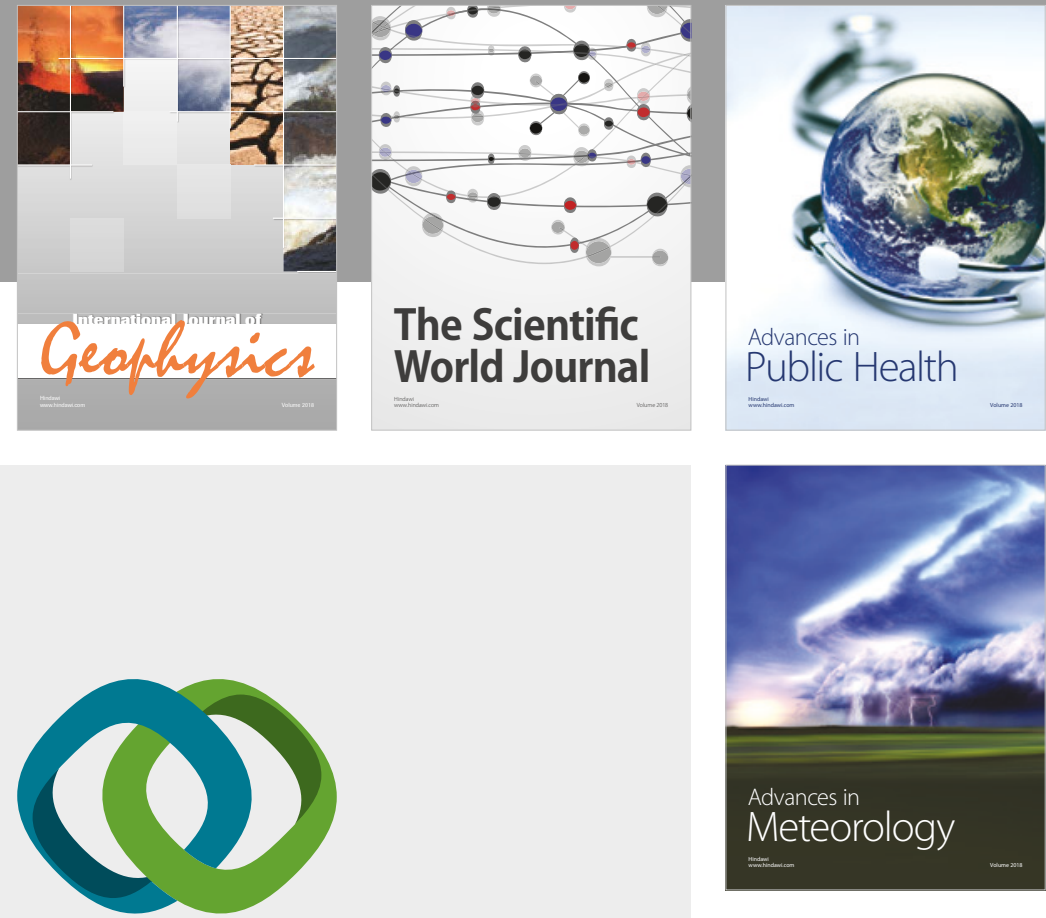

Advan

Public Health

\section{Hindawi}

Submit your manuscripts at

www.hindawi.com
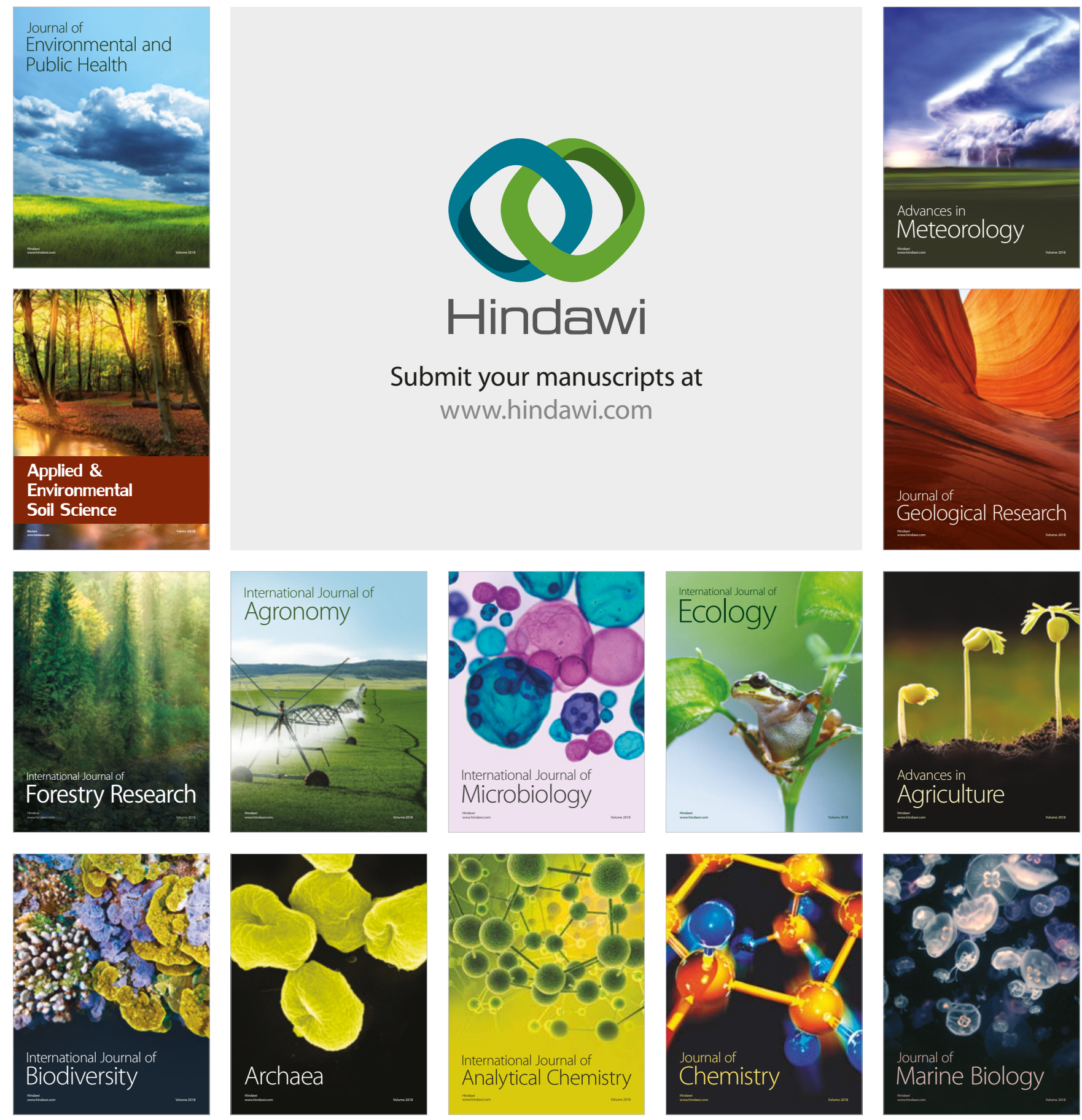